\title{
Régimen jurídico de las Sociedades Laborales y Participadas (Análisis de la Ley 44/2015, de 14 de octubre)
}

\author{
Luis Díez Acimas
}

Sumario: 1. Evolución de la normativa reguladora. 1.1. Artículo 129.2 de la Constitución Española. 1.2. Orden del Ministerio de Trabajo de 12 de enero de 1979. 1.3. Ley 15/1986, de 25 de abril, se Sociedades Anónimas Laborales. 1.4. Ley 4/1997, de 24 de marzo, de Sociedades Laborales. 1.5. Ley 5/2011, de 29 de marzo, de Economía Social. 1.6. Ley 44/2015, de 14 de octubre, de Sociedades Laborales y Participadas. 2. Regulación del régimen societario de las sociedades laborales en la Ley 44/2015, de 14 de octubre, de Sociedades Laborales y Participadas. 2.1. Concepto. 2.2. Capital social. Clases de acciones y participaciones. 2.3. Derecho de adquisición preferente de acciones y participaciones. Transmisión voluntaria «inter vivos». 2.4. Valoración de las acciones y participaciones. 2.5. Transmisión «mortis causa». 2.6. Derecho de suscripción preferente. 2.7. Adquisición de la sociedad de sus propias acciones. 2.8. Reserva Especial. 2.9. Supuestos de incumplimiento de los requisitos exigidos por la normativa. 2.10. Extinción de la relación laboral del socio trabajador. 2.11. Separación y exclusión de socios. 2.12. Pérdida de la calificación. 3. Aspectos formales y organizativos. Registro de Sociedades Laborales. 3.1. Competencia administrativa. 3.2. Registro Administrativo de Sociedades Laborales y coordinación con el Registro Mercantil. 3.3. Denominación social. 3.4. Órgano de administración. 3.5. Adaptación de estatutos. 4. Régimen de Seguridad Social de los socios trabajadores. 5. Régimen fiscal de las sociedades laborales. 6. Medidas de fomento. 7. Asociacionismo. 8. Regulación de las sociedades participadas en la Ley 44/2015, de 14 de octubre, de Sociedades Laborales y Participadas. 8.1. Fundamento y principios. 8.2. Concepto de sociedad participada por los trabajadores. 8.3. Reconocimiento. 8.4. Críticas a esta regulación. 9. Conclusiones. Bibliografía.

Resumen: La Ley 44/2015, de Sociedades Laborales y Participadas, regula, en primer lugar, las sociedades laborales, figura societaria que se ha convertido en el instrumento jurídico más utilizado por los trabajadores para convertirse, de forma colectiva, en empresarios y gestores de su propia empresa; y, por otro lado, regula por primera vez, en el ordenamiento jurídico español, las sociedades participadas. 
En este artículo, analizamos la evolución de la regulación de las sociedades laborales en España, constatando que las ideas básicas del concepto han cambiado muy poco, desde sus orígenes hasta la Ley 44/2015. Algunas de las modificaciones recogidas en esta última regulación, dotan de mayor flexibilidad a estas sociedades para poder obtener y mantener la calificación como laboral, lo cual, no tiene que valorarse, necesariamente, como positivo.

Estudiamos, también, las notas definitorias que de las sociedades participadas se hace en esta ley. Entendemos que la regulación de éstas es muy escueta; y, a la vez, muy abierta en la formulación de la idea misma de estas sociedades, por lo que creemos que debería haberse optado por una normativa más completa.

Palabras clave: Sociedad laboral, empresa participada, socio trabajador, participación, fomento.

Abstact: Law 44/2015, October, 14 th, Sociedades Laborales y Participadas. This law regulates, on the one hand, the labor societies a social figure which it has become the most used legal instrument used by workers to become collectively entrepreneurs and managers of their own company. On the other hand it is regulated for the first time in the Spanish legal system the investees societies.

In this article we analyze the evolution of the regulation of the labor societies in Spain, noting that the basic ideas of the concept have changed very little from its origins to the Law 44/2015. Some of the modifications in the latter regulation provide it with greater flexibility to these companies to obtain and maintain qualification as labor societies, which does not have to be assessed as positive.

We also studied the defining notes that are made in this law about investees societies. We think that the regulation of these societies is very short but at the same time it also allowed a broad interpretacion of this kind of societies. So we believe it should have done a more comprehensive legislacion.

Keywords: Labor society, investees societies, worker partner, emption, foment. 


\section{Evolución de la normativa reguladora}

En la regulación de las sociedades laborales en España, podemos destacar seis hitos normativos que nos marcan claramente el devenir de esta figura societaria que se ha convertido en el instrumento jurídico más utilizado por los trabajadores para convertirse, además, de forma colectiva, en empresarios y gestores de su propia empresa. En las diferentes regulaciones se puede constatar que las ideas básicas del concepto han cambiado muy poco, tan solo han sido adaptaciones para ofrecer una mayor simplificación y flexibilidad a este modelo empresarial, pero partiendo de unas premisas que han perdurado en la normativa aplicable desde el origen de las sociedades laborales.

Estas seis normas a las que nos referimos, son la Constitución Española de 1978; la Orden del Ministerio de Trabajo de 12 de enero de 1979; la Ley 15/1986, de 25 de abril, de Sociedades Anónimas Laborales; la Ley 4/1997, de 24 de marzo, de Sociedades Laborales; la Ley 5/2011, de 29 de marzo, de Economía Social y la Ley 44/2015, de 14 de octubre, de Sociedades Laborales y Participadas. Esta última norma supone que, por primera vez, el ordenamiento jurídico español contemple la figura de las sociedades participadas, aunque no podemos obviar que el principal referente de éstas en nuestro país son las sociedades laborales.

A continuación, vamos a analizar la evolución de la regulación de las sociedades laborales en los aspectos más relevantes para la configuración de este modelo y las notas definitorias que de las sociedades participadas hace la última norma citada.

\subsection{Artículo 129.2 de la Constitución Española (C.E.)1}

La figura de la sociedad laboral tiene reconocimiento constitucional, aunque sin citarla expresamente, como ocurre en el caso de las sociedades cooperativas, en el artículo 129.2 de la Constitución Española de 1978, que ordena tres actuaciones a los poderes públicos:

1. La promoción de las diversas formas de participación en la empresa.

1 El artículo 129.2 C.E.: 2. «Los poderes públicos promoverán eficazmente las diversas formas de participación en la empresa y fomentarán mediante una legislación adecuada, las sociedades cooperativas. También establecerán los medios que faciliten el acceso de los trabajadores a la propiedad de los medios de producción». 
2. El fomento mediante una legislación adecuada de las sociedades cooperativas.

3. El establecimiento de las medidas que faciliten el acceso de los trabajadores a la propiedad de los medios de producción.

Este precepto constitucional hace varias afirmaciones de trascendencia, como señala Calvo Ortega ${ }^{2} ; y$, todas ellas de futuro. El texto indica «promoverán, fomentarán y establecerán». Por tanto, imperatividad y futuro son las notas que se extraen de esta norma. Ahora bien, estos caracteres no significan que estemos ante una disposición que pueda o no cumplirse, o que pueda calificarse de norma programática. Se trata de una orden explícita que exige a los poderes públicos fomentar la acción y la participación de los trabajadores en la empresa. Es un mandato del constituyente a todos los poderes públicos, tanto estatales, como autonómicos; e, incluso, locales. Es, en palabras del mismo profesor, un mandato rotundo, de portada muy amplia que ha sido aplicado de manera discreta en forma de algunas medidas favorables a la tributación y a las subvenciones vinculadas normalmente a la creación de puestos de trabajo 3 .

El Tribunal Constitucional ha declarado, en constante jurisprudencia, que las normas constitucionales, lejos de poseer un significado simplemente programático, necesitado de ulterior desarrollo legislativo para adquirir validez y eficacia, tienen un carácter obligatorio y vinculante con proyección general, que alcanza consecuentemente al completo elenco de poderes públicos, de un lado, así como a la totalidad de ciudadanos de otro 4 .

El problema puede manifestarse al plantearnos cómo pueden exigir los ciudadanos a estos poderes que cumplan dicho mandato. Pero, la dificultad de la exigencia o de la concreción de lo exigible no puede empañar la claridad y la naturaleza vinculante del precepto.

2 CALVO ORTEGA, R., Las figuras de la Economía Social en la Constitución Española de 1978. CIRIEC-España, n. ${ }^{\circ}$ 47, 2003, pp. 159-174.

3 CAVO ORTEGA, R. Sociedades Laborales. Cuadernos Civitas. Editorial Aranzadi. Cizur Menor 2013, pág. 13.

4 El Tribunal Constitucional ha afirmado el valor normativo y la inmediata aplicabilidad de la Constitución, afirmando que «lejos de ser un mero catálogo de principios de no inmediata vinculación y de no inmediato cumplimento hasta su desarrollo por vía legal, es una norma jurídica, la norma suprema de nuestro Ordenamiento, y en cuanto tal, tanto los ciudadanos como los poderes públicos, y, por consiguiente, también los jueces y magistrados del poder judicial, están sujetos a ella» (STC 16/1982, de 28 de abril). En RODRIGO RUIZ, M.A., Mandato constitucional de fomento y fiscalidad de las cooperativas CIRIEC-España, n. ${ }^{4}$ 7, 2003, pp. 199-219. 
De cualquier manera, estamos ante una imprecisión relativa, según Calvo Ortega, ya que puede decirse que las normas deben de ser más favorables para este tipo de sociedades que para el modelo social que deba considerarse normal. La pregunta que nos formulamos es ¿en qué debe consistir esta mejor consideración legislativa? Puede ser administrativa, crediticia, de ayuda a la formación específica, tributaria, laboral, etc. Pero lo cierto es que tales normas tienen que ser más ventajosas desde una perspectiva patrimonial (que es la única que aquí puede contemplarse) que las que se aplican a los otros sujetos societarios.

Es difícil decir si el precepto constitucional que estamos examinando ha jugado un papel importante en la creación de sociedades cooperativas y, especialmente, en este caso, de sociedades laborales. Aunque podamos mostrar cifras positivas del periodo constitucional, siempre queda la duda, según Calvo Ortega, de saber si el desarrollo que se ha producido es debido al revulsivo de incluir este precepto en la norma constitucional o a otras razones. Entre éstas, destaca el esfuerzo admirable de muchos trabajadores creando y manteniendo empresas asociativas en condiciones, muchas veces, difíciles.

Referiremos, a continuación, la plasmación que se ha hecho en la normativa de este triple mandato constitucional.

\subsubsection{LA PROMOCIÓN DE LAS DIVERSAS FORMAS DE PARTICIPACIÓN EN LA EMPRESA}

La obligación constitucional de facilitar la participación de los trabajadores en la empresa tiene diversas manifestaciones en la normativa promulgada con posterioridad a la CE, tales como:

El Real Decreto Legislativo 2/2015, de 23 de octubre, por el que se aprueba el texto refundido de la Ley del Estatuto de los Trabajadores, configura como un derecho básico de los trabajadores en la relación laboral la información, consulta y participación (artículo $4.1 \mathrm{~g}$ ). Así como la regulación de los delegados de personal y comités de empresa, consagrando la participación a través de estos órganos, aunque el artículo 61 reconoce otras fórmulas al añadir expresamente «sin perjuicio de otras formas de participación».

La Ley Orgánica 11/1985, de 8 de agosto de Libertad Sindical, que regula la acción sindical en el seno de la empresa.

La Ley 31/1995, de 8 de marzo, de Prevención de Riesgos Laborales, que prevé los mecanismos de consulta y participación de los trabajadores en las cuestiones de prevención de riesgos laborales.

Ley 22/2003, de 9 de julio, Concursal, que otorga a los representantes de los trabajadores competencias para ser oídos, en asuntos tales como el cierre de instalaciones del concursado o en la propuesta de convenio. 


\subsubsection{El FOMENTO MEDIANTE UNA LEGISLACIÓN ADECUADA DE LAS SOCIEDADES COOPERATIVAS}

En el cumplimiento de la obligación impuesta a los poderes públicos de fomentar las sociedades cooperativas, mediante una legislación adecuada, podemos constatar la existencia de una amplia normativa en la materia. Respecto a la regulación general de este tipo de sociedades, contamos con una Ley de Cooperativas estatal (Ley 27/1999, de 16 de julio), y dieciséis leyes autonómicas ${ }^{5}$. Además, de una legislación específica sobre cooperativas de crédito (básicamente la Ley 13/1989, de 26 de mayo) o una regulación del régimen fiscal propio de estas sociedades (Ley 20/1990, de 19 de diciembre, de Régimen Fiscal de las Cooperativas). El análisis de estas regulaciones, nos podría llevar al debate de si esa legislación es «adecuada», como exige la C.E. Evidentemente, este no es el lugar para plantear esa discusión.

\subsubsection{El eSTABLECIMIENTO DE LAS MEDIDAS QUE FACILITEN EL ACCESO DE LOS TRABAJADORES A LA PROPIEDAD DE LOS MEDIOS DE PRODUCCIÓN}

En el último inciso de este artículo, se identifica la participación con la propiedad de la empresa. Este precepto ofrece extraordinarias posibilidades para la actuación política, tanto en la selección de los mecanismos de participación como en la determinación cualitativa de los mismos.

Esto se plasma en la promoción de fórmulas fundamentalmente de carácter económico-financiero que contribuyan a la superación de los condicionantes que limitan el acceso a la propiedad de esos bienes y faciliten el acceso al accionariado por parte de los trabajadores. Manifestaciones características de este proceso son las diferentes legislaciones que se han promulgado para regular las sociedades laborales $y$, ahora, las sociedades participadas, cuya finalidad es conseguir nuevos modelos de creación de empleo y fomentar la participación de los trabajadores en la empresa, dando cumplimiento, así, a este mandato constitucional.

5 Únicamente, la Comunidad Autónoma de Canarias no dispone de ley propia en materia de sociedades cooperativas. 


\subsection{Orden del Ministerio de Trabajo de 12 de enero de 1979}

Las sociedades laborales nacen, sin una legislación específica, al amparo de la Ley de 21 de julio de 1960, de Creación del Fondo Nacional de Protección al Trabajo. Este fondo tiene por finalidad «Conceder auxilio necesario a aquellos trabajadores que de acuerdo con la legislación vigente, cesen en su relación laboral por aplicación de los planes que para una mayor racionalización del trabajo y para el desarrollo y mejoramiento de sus instalaciones presenten las empresas o sectores completos de una rama industrial y sean aprobados por el Gobierno».

Esta Orden de 12 de enero de 1979, destinada a regular las ayudas de este Fondo para ese año, es considerada por Calvo Ortega, quien firma la misma como Ministro de Trabajo, como el nacimiento de las sociedades laborales y el motivo, por su fecha, de que la CE no cite esta figura empresarial. El capítulo III del XVIII Plan de Inversiones del Fondo Nacional de Protección al Trabajo, bajo el título de promoción social de los trabajadores, contempla acciones de asistencia económica, de asistencia técnica y de formación comunitaria que tienen como destinatarios a las cooperativas de trabajo asociado y a las sociedades laborales. En esta orden, se dice expresamente que en los estatutos de estas últimas entidades deberá constar necesariamente que, al menos, el 50 por ciento del capital social tiene que pertenecer a los trabajadores, que ningún socio pueda tener más del 25 por ciento del capital social y que los títulos pertenecientes a los trabajadores, sólo podrán transmitirse a otros trabajadores de la empresa.

Como podemos ver, se exige mayoría del capital social en manos de los trabajadores de la empresa, que ningún socio pueda ser titular de más capital que el establecido en la norma y un régimen restrictivo de transmisión de las participaciones de los trabajadores, con lo que tenemos perfilados los elementos definidores básicos del concepto de sociedad laboral, a falta únicamente de la limitación de prestación de servicios por trabajadores indefinidos no socios, que van a caracterizar a esta figura en las normativas posteriores.

En los años siguientes, y vía órdenes de convocatorias de ayudas de este fondo, con la finalidad de facilitar a los trabajadores la adquisición de acciones de sus empresas para tratar de salvarlas de su desaparición, nacen numerosas sociedades laborales, como método de hacer frente al cierre de empresas y pérdidas de empleos. Se configura como fórmula de autoempleo colectivo por parte de los trabajadores, que cuenta con el apoyo de los Gobiernos de la Transición y donde desempeñan un papel básico los sindicatos de trabajadores, en aquel momento, recientemente legalizados. 


\subsection{Ley 15/1986, de 25 de abril, de Sociedades Anónimas Laborales}

El Ministerio de Trabajo y Seguridad Social venía regulando mediante Orden Ministerial anual las condiciones que deberían cumplir las sociedades civiles y mercantiles para ser consideradas como laborales y así equipararse en ayudas a las cooperativas de trabajo asociado, pero la falta de regulación jurídica suficiente de estas sociedades dificultaba su promoción, quedando esta limitada al área financiera, hasta que se promulgó la Ley 15/1986, de 25 de abril, de Sociedades Anónimas Laborales.

Se promulga en un momento en que el sector industrial pasa por graves dificultades, lo que ocasiona que nos enfrentemos al cierre de numerosas empresas con la consiguiente pérdida de empleo. Ante la necesidad de dar una respuesta positiva a esta situación, los trabajadores, dan un paso adelante, toman la iniciativa y adoptan nuevos métodos de creación de empleo mediante la constitución de esta forma empresarial.

En la mayoría de los casos, este paso supone un proceso de reconversión de la empresa anterior, lo que exige un redimensionamiento, un cambio de forma jurídica y de titularidad de la empresa.

Esta norma va a otorgar seguridad jurídica a estas empresas, al establecer los requisitos para su consideración como laborales, y a la vez va articular una serie de medidas tendentes a fomentar adecuadamente esta fórmula de organización económica y de participación de los trabajadores en la empresa y establece los sistemas de control que eviten la incorrecta utilización de esta figura societaria.

Ya establece las características básicas de las sociedades laborales, que van a aparecer, con ligeras modificaciones, en las sucesivas normas, como elementos definidores de esta forma empresarial:

La mayoría del capital social (al menos el 51 por 100) debe pertenecer a los trabajadores que presten en ellas servicios retribuidos en forma directa, personal, cuya relación laboral lo sea por tiempo indefinido y a jornada completa.

Ninguno de los socios podrá poseer acciones que representen más del 25 por 100 del capital social. Esta norma tiene una excepción, al permitir que podrán participar en el capital de las sociedades anónimas laborales, hasta el 49 por 100, las entidades públicas, así como las personas jurídicas en cuyo capital social participen mayoritariamente o pertenezca en su totalidad al Estado, las comunidades autónomas y las entidades locales.

El número de trabajadores cuya relación laboral sea por tiempo indefinido y que no tengan suscritas y desembolsadas acciones de la 
sociedad, no podrán ser superiores al 15 por 100 en relación al total de socios trabajadores, excepto en las constituidas por menos de 25 socios trabajadores, en los que el porcentaje máximo será del 25 por 100.

Las sociedades anónimas laborales, además de las reservas legales o estatutarias y con los mismos fines, vendrán obligadas a constituir un Fondo Especial de Reserva de carácter irrepartible, excepto en caso de liquidación, dotado con el 10 por 100 de los beneficios líquidos de cada ejercicio.

Se prevé la existencia de dos clases de acciones, las reservadas a los socios trabajadores, y las restantes.

Se establece un procedimiento especial para el supuesto de que se proponga la transmisión de acciones reservadas a los trabajadores a persona que no sea trabajador de la sociedad a tiempo completo.

La Ley 15/1986, de 25 de abril, de Sociedades Anónimas Laborales, fue, en el campo de la empresa, un paso importante en el cumplimiento del artículo 129.2 de la CE y un acicate para la constitución de las asociaciones empresariales representativas, tanto de ámbito autonómico como estatal, de este tipo de empresas.

\subsection{Ley 4/1997, de 24 de marzo, de Sociedades Laborales}

La profunda reforma llevada a cabo por la Ley 19/1989, de 25 de julio, de adaptación de las sociedades de capital a las normas comunitarias y el cambio de signo que había experimentado en los últimos años el marco societario en España, llevó a la aprobación de la Ley 2/1995, de 23 de marzo, de Sociedades de Responsabilidad Limitada. Este nuevo marco exige una regulación de las sociedades laborales acorde con dichos cambios y con las expresadas normas comunitarias.

Es sabido, según se dice en la Exposición de Motivos de la ley, que desde la citada reforma de 1989 la proporción de sociedades que adoptan la forma de responsabilidad limitada ha pasado de ser un número exiguo, antes de dicha fecha, a elevarse hasta el 92 por 100 de todas las que se constituyen. A esto se añade que la nueva Ley de Sociedades de Responsabilidad Limitada permite una mayor flexibilidad que la sociedad anónima. El menor importe de la cifra de capital, los menores gastos de constitución, el número ilimitado de socios y los tintes personalistas que se conjugan con su condición de sociedad de capital son algunas de las características de la sociedad limitada, que la hacen más apta como fórmula jurídica de organización económica para 
los trabajadores y como vehículo de participación en la empresa. Las nuevas exigencias de capital social mínimo en las sociedades anónimas, suponen un importante obstáculo para la creación de sociedades anónimas laborales.

Ante este panorama, la ley, que es fruto de una proposición del Grupo Parlamentario Socialista, entonces en una recientemente estrenada labor de oposición y que fue secundada, entre otros, por el Grupo Parlamentario Popular, que sustentaba al Gobierno, opta por los dos tipos societarios (anónima y limitada), dejando a la voluntad de los promotores la adopción de una u otra forma.

La nueva regulación, según se indica en el preámbulo de la ley, respeta las líneas maestras del concepto de sociedad laboral entre las que cabe señalar: que la mayoría del capital sea propiedad del conjunto de los socios trabajadores que prestan en ella servicios retribuidos en forma personal y directa, cuya relación laboral lo sea por tiempo indefinido; fijación de un límite al conjunto de los trabajadores no socios contratados por tiempo indefinido; fijación del máximo de capital que puede poseer cada socio; existencia de dos tipos de acciones o participaciones según sus propietarios sean trabajadores o no; derecho de adquisición preferente en caso de transmisión de las acciones o participaciones de carácter laboral; constitución de un fondo de reserva especial destinado a compensar pérdidas. Todas ellas constituyen sus notas esenciales que junto con las bonificaciones fiscales contribuyen a la promoción y desarrollo de este tipo de sociedad.

Además, de admitir la opción de que la sociedad sea limitada, se aprecian las nuevas características siguientes:

Se suprime el requisito de que la jornada de los socios trabajadores sea a tiempo completo.

Ninguno de los socios podrá poseer acciones o participaciones sociales que representen más de la tercera parte del capital social (lo que supone la reducción del número mínimo de socios a tres), salvo que se trate de sociedades laborales participadas por el Estado, las comunidades autónomas, las entidades locales o las sociedades públicas participadas por cualquiera de tales instituciones, en cuyo caso la participación de las entidades públicas podrá superar dicho límite, sin alcanzar el 50 por 100 del capital social. Igual porcentaje podrán ostentar las asociaciones u otras entidades sin ánimo de lucro.

Se sigue regulando la obligación de constituir un Fondo Especial de Reserva, que se dotará con el 10 por 100 del beneficio líquido de cada ejercicio. En esta ley, se añade la finalidad de dicho fondo (al que ya 
no califica de irrepartible), al establecer que sólo podrá destinarse a la compensación de pérdidas en el caso de que no existan otras reservas disponibles suficientes para este fin.

Se modifica el criterio de número de trabajadores indefinidos no socios por el de horas/año trabajadas por los trabajadores contratados por tiempo indefinido que no sean socios, manteniéndose la diferencia en función de si la empresa tiene más o menos de veinticinco socios trabajadores. Para el cómputo del límite de horas, a partir del 1 de enero de 2004, se excluyen los trabajadores con discapacidad psíquica en grado igual o superior al 33 por ciento con contrato indefinido. (Modificación incluida por el artículo 45 de Ley $62 / 2003$, de 30 de diciembre, de medidas fiscales, administrativas y del orden social).

La Confederación Empresarial de Sociedades Laborales de España (CONFESAL), con especial énfasis a partir de 2007, plantea la necesidad de modificar la ley reguladora de las sociedades laborales, persiguiendo los siguientes objetivos, recogidos en la «Memoria de la reforma de la Ley de Sociedades Laborales» de 20096:

Aumentar la utilidad de las sociedades laborales y su preferencia por los emprendedores para dar forma jurídica societaria a su proyecto emprendedor.

Afirmar el carácter de opción empresarial válida tanto en momentos de crisis como de bonanza económica.

Recoger el resultado del éxito de las políticas de fomento del trabajo autónomo cuando evolucione a constituir sociedades, dando una opción empresarial participativa en el ámbito de la economía social.

Dar coherencia al fomento del espíritu emprendedor, basado en la participación de los trabajadores en la pequeña y mediana empresa.

De esta necesidad de modificación del régimen jurídico de las sociedades laborales, CONFESAL hace partícipe al Ministerio, entonces, de Trabajo e Inmigración y, posteriormente, de Empleo y Seguridad Social para trabajar en la elaboración de un nuevo texto que sirva de base para una nueva regulación de las sociedades laborales, que no se plasmará en una norma hasta 2015.

6 Se recoge en FAJARDO GARCÍA, G., ALGUACIL MARÍ, P., LÓPEZ GANDÍA, J. «Propuesta de reforma de la Ley de Sociedades Laborales 4/1997», en "Análisis sobre los cambios normativos necesarios para cooperativas y sociedades laborales para su adaptación al nuevo escenario económico». Ministerio de Trabajo e Inmigración, 2009. 


\subsection{Ley 5/2011, de 29 de marzo, de Economía Social (LES)}

El objetivo básico de esta ley es configurar un marco jurídico que, sin pretender sustituir la normativa vigente de cada una de las entidades que conforma el sector, suponga el reconocimiento y mejor visibilidad de la economía social, otorgando una mayor seguridad jurídica por medio de las actuaciones de definición de la economía social, estableciendo los principios que deben contemplar las distintas entidades que la forman. Partiendo de estos principios se recoge el conjunto de las diversas entidades y empresas que conforman la economía social. Asimismo, se reconoce como tarea de interés general, la promoción, estímulo y desarrollo de las entidades de la economía social y de sus organizaciones representativas.

La Ley 5/2011, de 29 de marzo, de Economía Social ha contribuido decisivamente a acotar y visualizar, según Montesinos Oltra7; un sector de la realidad social de cuya importancia difícilmente puede dudarse, tanto en términos cuantitativos como, sobre todo, cualitativos, que son los que permiten considerarlo un «polo de utilidad social» como se señala en el Informe de la Subcomisión para el Fomento de la Economía Social creada en el seno de la Comisión de Economía y Hacienda del Congreso de los Diputados y justifican el reconocimiento de tratamientos favorecedores o promocionales desde la perspectiva de la actividad financiera de las Administraciones Públicas.

¿Qué entiende esta norma por economía social? ${ }^{8}$ Se obtiene, de la lectura de la misma, un resultado que dista mucho de alcanzar las cualidades que debe reunir una definición de la economía social en opinión de Calvo Ortega ${ }^{9}$, que con anterioridad a promulgarse la ley, manifestaba que «debe buscar su núcleo, ser sencilla y, por supuesto, ser válida para la diversidad de actividades que se engloban bajo este rótulo». Y, de forma coherente con este postulado el referido autor proponía la siguiente definición: «La economía social es un actividad de in-

7 MONTESINOS OLTRA, S., La Ley de Economía Social, interés general y regímenes tributarios especiales. CIRIEC-España, Revista Jurídica n. ${ }^{\circ}$ 23/2012, pp. 1-27.

8 De acuerdo con la ley, se denomina economía social al conjunto de las actividades económicas y empresariales, que en el ámbito privado llevan a cabo aquellas entidades que, de conformidad con los principios recogidos en la propia ley, persiguen bien el interés colectivo de sus integrantes, bien el interés general económico o social, o ambos.

9 CALVO ORTEGA, R., Entidades de Economía Social: Razones de una fiscalidad específica, en Fiscalidad de las entidades de Economía Social, Thomson-Civitas, Cizur Menor, 2005, pp. 33-63. 
terés general realizada por sujetos empresariales privados a los que la ley limita sus facultades dominicales».

La promulgación de la LES, pone fin, al menos, de forma momentánea, al intenso debate, no siempre pacífico, vivido desde el ámbito doctrinal, el sector empresarial en su conjunto y de las entidades asociativas de las diferentes realidades que se consideraban merecedoras de llevar esta etiqueta. Este debate, incluso, veía su reflejo en las diferentes Administraciones Públicas que incluían más o menos tipología de empresas dentro de su ámbito de actuación, dentro de las estructuras administrativas dedicadas a economía social.

La ley fija, por primera vez, en una norma jurídica, cuáles son las empresas que forman parte de este sector. Al citar las entidades que constituyen el sector de la economía social, que se recogen en el artículo 5, entre las que figuran expresamente las sociedades laborales.

Para las políticas de fomento del cooperativismo y de la economía social en España, esta ley es un punto de inflexión; realmente, abre, al menos teóricamente, una nueva etapa en esta materia. $Y$, decimos teóricamente, porque está pendiente una necesaria y apasionante labor de desarrollo de esta ley.

Destacan dos aspectos en los que se aprecia el nuevo marco en el que se mueve este sector:

Reconocimiento de este sector socioeconómico como un interlocutor social en los procesos de elaboración de las políticas públicas (artículo 9).

Concepción de una amplia gama de políticas de fomento de la economía social (artículo 8).

Las sociedades laborales, por sus fines y principios orientadores, son entidades de la economía social, que son recogidas expresamente, como decíamos anteriormente, en el catálogo de entidades que establece la LES. Suberbiola Garbizu ${ }^{10}$ concreta cómo las sociedades laborales recogen los principios orientadores contemplados en el artículo 4 de dicha ley, en la medida siguiente:

1. La primacía de las personas que componen su accionariado y el fin social de estas entidades se concreta en una gestión autónoma, transparente, democrática y participativa.

2. Se aplican los resultados obtenidos de la actividad económica al fin social del objeto de la sociedad.

10 SUBERBIOLA GARBIZU, I. «Régimen tributario de las sociedades. Propuesta de reforma» CIRIEC n. ${ }^{\circ} 10,2013$, pp. 7-52. 
3. Se proporciona la solidaridad interna y con la sociedad mediante el impulso de la cohesión social, la generación de empleo estable y de calidad.

4. Mantienen su independencia respecto a los poderes públicos.

Por tanto, deben ser acreedoras de sus políticas de promoción, entre las que figura el mandato a los poderes públicos de crear un entorno que fomente el desarrollo de iniciativas económicas y sociales en el marco de la economía social. Con este objetivo, la disposición adicional séptima de esta ley, dentro del programa de impulso de las entidades de economía social, ordena al Gobierno que remita a las Cortes un proyecto de ley que actualice y revise la Ley 4/1997, de 24 de marzo, de Sociedades Laborales; para lo que otorgaba un plazo de seis meses.

En esta línea cabe destacar que las sociedades laborales en España en sintonía con las recomendaciones europeas responden al modelo de empresa participada mayoritariamente. Son unos de los máximos exponentes de la participación de los trabajadores en las empresas en nuestro país, encontrándose a la vanguardia en relación a la regulación de este tipo de entidades en los restantes países de nuestro entorno.

\subsection{Ley 44/2015, de 14 de octubre, de Sociedades Laborales y Participadas (LSSLLYPP)}

La Ley 4/1997, de 24 de marzo, de Sociedades Laborales, introdujo un importante avance en la regulación de éstas y permitió un gran desarrollo de esta fórmula societaria, como se puede constatar a la vista de la creación de numerosas empresas y puestos de trabajo que se han generado al amparo de dicha norma. El hecho de admitir la fórmula de sociedad limitada laboral con un capital social inferior a las anónimas fue un importante revulsivo de este tipo de sociedades.

No obstante, dado el tiempo transcurrido desde su promulgación comienza a evidenciarse, según se dice en la exposición de motivos de la ley, la necesidad de actualizar su marco normativo con el objetivo de dar un nuevo impulso a las sociedades laborales por su condición de empresas participadas por los socios trabajadores, y abiertas a la integración como socios de los demás trabajadores de la empresa.

La nueva regulación no solo actualiza, moderniza y mejora el contenido de la Ley 4/1997, de 24 de marzo, como consecuencia de las últimas reformas del derecho de sociedades, sino que en cumplimiento de la previsión contenida en la Ley 5/2011, de Economía Social, refuerza la naturaleza, función y caracterización de la sociedad laboral como en- 
tidad de la economía social, poniendo en valor sus especificidades, ya que las sociedades laborales son sociedades de capital por su forma; y, por tanto, le son aplicables las normas relativas a las sociedades anónimas y limitadas; pero, sin que se pueda perder de vista, en ningún momento, su carácter de entidad de economía social.

Esta ley supone, también, el cumplimiento, aunque retrasado, de la obligación impuesta por la referida LES.

La ley se fija los siguientes objetivos:

La mejora del régimen jurídico de estas sociedades, fomentando la participación de los trabajadores en las empresas y facilitando su acceso a la condición de socio.

Incorporación de nuevas medidas para asegurar el control de la sociedad por parte de los trabajadores.

Aumentar la utilidad de las sociedades laborales y su preferencia por parte de los emprendedores. Pretende fortalecer su vertiente empresarial y consolidar el carácter estable y no coyuntural de este modelo empresarial.

Prepara su contenido a los cambios que se producirán en torno al documento único electrónico.

Reestructura el articulado eliminando preceptos superfluos e incorporando otros necesarios.

El capítulo III de esta ley regula las sociedades participadas por los trabajadores, definiendo por primera vez en nuestro país dicho concepto, considerando como tales no solo a las propias sociedades laborales, sino a cualesquiera otras sociedades en las que los socios trabajadores posean capital social y derechos de voto. Establece además los principios a los que se someten, y el posible reconocimiento que se pueda otorgar a estas sociedades, mediante las oportunas normas de desarrollo.

\section{Regulación del régimen societario de las Sociedades Laborales en la LSSLLyPP}

Esta ley solamente regula los aspectos que son específicos de las sociedades laborales en cuanto tales, como las condiciones para que las sociedades puedan obtener la calificación de laboral, el mantenimiento de tal condición, las peculiaridades de éstas por ostentar tal naturaleza; pero, la mayor parte de su régimen jurídico vendrá dado por otras normas, especialmente, en los aspectos societarios, por el Real Decreto Legislativo 1/2010, de 2 de julio, por el que se aprueba el texto refundido de la Ley de Sociedades de Capital. Así, la disposición final tercera de la 
LSSLLyPP establece que «en lo no previsto en esta ley, serán de aplicación a las sociedades laborales las normas correspondientes a las sociedades anónimas o de responsabilidad limitada, según la forma que ostenten».

\subsection{Concepto}

El artículo 1, se dedica a recoger todos los elementos que van a determinar la configuración de una sociedad como laboral, a diferencia de la ley anterior en la que se dispersaban estos requisitos por varios artículos. Asimismo, contempla los incumplimientos sobrevenidos de estos requisitos y la acomodación, en su caso, de nuevo a las previsiones de la ley, cuando se hayan producido esos incumplimientos.

Las sociedades laborales son aquellas sociedades anónimas o de responsabilidad limitada que cumplen los siguientes requisitos para que puedan obtener la calificación «laboral».

a) Condiciones relativas a la titularidad del capital social. Al menos, la mayoría del capital social debe ser propiedad de trabajadores que presten en ellas servicios retribuidos de forma personal y directa, en virtud de una relación laboral por tiempo indefinido. No exige, como ya ocurría en la anterior ley, que estos estén vinculados a jornada completa con la sociedad, como establecía la ley de 1985.

Este requisito define la esencia de las sociedades laborales, es decir, la necesidad de que el capital social sea mayoritariamente de titularidad de los trabajadores.

b) Condiciones relativas a la distribución del capital social. Ningún socio podrá ser titular de acciones o participaciones sociales que representen más de la tercera parte del capital social. Esta exigencia de porcentaje máximo busca un equilibrio entre la mayor aportación a la sociedad (es decir, un liderazgo), de una parte; y, de otro lado, la necesaria formación de la voluntad social con criterios democráticos. Como señala, Calvo Ortega ${ }^{11}$, la sociedad laboral en materia de formación de voluntades, constituye un tipo intermedio entre la sociedad anónima y la sociedad cooperativa de trabajo, ya que la sociedad laboral se rige por criterios de capital, pero con apertura a criterios democráticos, ya que ningún socio puede tener más de un tercio del capital social. 
Existen dos excepciones a esta exigencia:

1. Que la sociedad laboral se constituya inicialmente por dos socios trabajadores con contrato por tiempo indefinido. En este caso, tanto el capital social como los derechos de voto estarán distribuidos necesariamente al cincuenta por ciento. Estas sociedades deberán adaptarse a lo previsto con carácter general en la ley en un plazo máximo de treinta y seis meses. Al exigir que los dos socios sean de trabajo, no se modifica mucho la situación real actual, en la que hay muchas sociedades con tres o cuatro socios, pero solo dos con la condición de trabajadores. En cualquier caso, la ley contempla este supuesto como transitorio durante los tres primeros años de vida de la empresa, optando porque las sociedades laborales, como regla general, cuenten con, al menos, tres socios.

2. Se trate de socios que sean entidades públicas, de participación mayoritariamente pública, entidades no lucrativas o de la economía social, en cuyo caso la participación podrá superar dicho límite, sin alcanzar el cincuenta por ciento del capital social. Se añaden, ahora, en esta excepción a las entidades de la economía social.

c) Condiciones relativas al volumen de trabajo realizado por trabajadores contratados por tiempo indefinido que no sean socios. Se exige que el número de horas-año trabajadas por éstos no sea superior al cuarenta y nueve por ciento del cómputo global de horas-año trabajadas en la sociedad laboral por el conjunto de los socios trabajadores. No computará para el cálculo de este límite el trabajo realizado por los trabajadores con discapacidad de cualquier clase en grado igual o superior al treinta y tres por ciento. Como se puede apreciar, se amplía esta excepción, que en la regulación anterior solo incluía a las personas con discapacidad psíquica.

Se observa, aquí, un cambio sustancial respecto a la ley de 1997, que establecía el quince por ciento y el veinticinco por ciento en función de que la sociedad tuviese más o menos de veinticinco socios trabajadores. Este aumento del volumen de horas-año, independientemente de la dimensión de la sociedad, es objeto de crítica en el dictamen del Consejo Económico y Social (CES) al anteproyecto de ley ${ }^{12}$,

12 Dictamen 6/2015. Aprobado en sesión extraordinaria del Pleno de 13 de mayo de 2015. Disponible en www.ces.es 
al entender que, si bien, puede favorecer el funcionamiento de las sociedades laborales; sin embargo, puede entrar en colisión con los principios sustanciales sobre los que se sustentan; y, por tanto, afectar al concepto mismo de sociedad laboral.

Este mecanismo de limitación del trabajo por parte de trabajadores no socios, vinculados con contrato indefinido a la sociedad debería facilitar la conversión de trabajadores en socios. Pero, en la práctica, la aplicación de esta norma puede desembocar en situaciones de abuso de la contratación temporal, excediendo los límites legales al respecto, al encadenar numerosos contratos temporales sin reconocer el carácter indefinido de la relación laboral, algo contradictorio con la propia naturaleza de estas sociedades. En otras ocasiones, el problema viene dado porque los trabajadores no quieren ser socios, lo que no debería originar la descalificación de la sociedad, ni resolver el posible problema planteado en ese caso, con despidos de trabajadores que no deseen acceder a la condición de socios. La ley no se pronuncia sobre la negativa de los trabajadores a ser socios, como se contempla habitualmente en la legislación sobre cooperativas.

Este requisito fue objeto de enmienda, por el Grupo Parlamentario Izquierda Plural, que no fue aprobada, para reducir sustancialmente esta proporción (al quince por ciento, en todo caso), al entender que una flexibilización de este tipo puede acarrear el riesgo de desnaturalización de este tipo de sociedades.

Tal vez, el precepto debería de haber recogido, también, las contrataciones no indefinidas para establecer un límite que contemplara en conjunto las contrataciones temporales e indefinidas y ofrecer la posibilidad de contratación temporal extraordinaria, y autorizada por la administración competente, en periodos punta de actividad, como se hace habitualmente en la legislación de sociedades cooperativas.

\subsection{Capital social. Clases de acciones y participaciones}

Respecto al capital social mínimo de este tipo de entidades, habrá que atender a lo previsto al respecto en la Ley de Sociedades de Capital. Por lo tanto, no podrá ser inferior a $3.000 €$ en el caso de las sociedades limitadas laborales y a $60.000 €$ cuando se trate de las sociedades anónimas laborales El capital social, de acuerdo con el artículo 5.1 de la LSLLyPP, estará dividido en acciones nominativas o en participaciones sociales. Las acciones y participaciones, sean de la clase que sean, tendrán el mismo valor nominal y conferirán los mismos derechos. No creemos que en una figura empresarial de economía social tenga fá- 
cil justificación la existencia de acciones privadas del derecho de voto u otros derechos o que tengan algún privilegio sobre otras, por lo que esta previsión se considera adecuada. Además, al exigir que todas las participaciones tengan el mismo valor, se garantiza que los socios trabajadores, que necesariamente tendrán la mayoría del capital social, tendrán también el control efectivo de la sociedad.

El artículo 5.2, establece que las acciones y participaciones de las sociedades laborales se dividirán en dos clases:

Clase laboral: Aquellas que son propiedad de los trabajadores cuya relación laboral lo sea por tiempo indefinido.

Clase general: Las restantes.

La sociedad laboral podrá ser titular de acciones y participaciones de ambas clases.

\subsection{Derecho de adquisición preferente de acciones y participaciones, transmisión voluntaria «inter vivos»}

La regulación de esta materia, parte de una premisa básica, que es el interés por la conservación de la mayoría del capital social en manos de los trabajadores, lo que resulta necesario para mantener la laboralidad de la sociedad, y eso exige la regulación de un derecho de adquisición preferente que garantice el mantenimiento de esa mayoría.

El objetivo propuesto por el nuevo texto legal en esta materia es la simplificación del procedimiento de transmisión de acciones y participaciones, haciéndolo más ágil que el regulado anteriormente. Se contemplan dos supuestos diferentes en el artículo 6 de la ley:

a) Transmisión a socios trabajadores y trabajadores no socios vinculados a la empresa con contrato por tiempo indefinido. Salvo previsión estatutaria en contra, las acciones y participaciones podrán transmitirse libremente a las personas en que concurran dichas circunstancias. En este supuesto, la ley impone al transmitente la obligación de comunicar a los administradores de la sociedad, por escrito y de modo que asegure su recepción, el número y características de las acciones o participaciones que se proponga transmitir y la identidad del adquiriente.

b) En los demás supuestos, hay que seguir el procedimiento previsto en el artículo 6.2 de la ley.

El procedimiento se inicia con la comunicación por parte del propietario de las acciones o participaciones a la sociedad del número, ca- 
racterísticas y términos económicos de las acciones o participaciones que se proponga transmitir.

La sociedad dará traslado de la propuesta, en el plazo máximo de diez días, simultáneamente, en lugar de sucesivamente, como preveía la ley anterior, a todos los posibles interesados (trabajadores indefinidos, socios trabajadores y socios generales). Estos disponen de un plazo de veinte días para manifestar su voluntad de adquisición.

Recibidas las ofertas de compra, los administradores en el plazo de diez días comunicarán al vendedor la identidad del o de los adquirentes, priorizándose los interesados.

En caso de concurrencia de solicitudes de adquisición, se seguirá el siguiente orden de preferencia en la adjudicación de las acciones o participaciones:

1. Trabajadores indefinidos no socios, en relación directa a su antigüedad en la empresa.

2. Socios trabajadores, en relación inversa al número de acciones o participaciones que posean.

3. Socios de la clase general, a prorrata de su participación en el capital social.

4. Sociedad.

Como puede apreciarse, en primer lugar, se pretende que se incorporen trabajadores a la condición de socios; y, en segundo, facilitar el equilibrio de las participaciones de los socios trabajadores. Se observa que desaparece la preferencia de los trabajadores con contrato de duración determinada que se recogía en la legislación anterior. Se entiende que ofrecer esta posibilidad puede generar efectos distorsionadores sobre la sociedad.

En el caso de que no se presentasen ofertas de compra en el plazo previsto al efecto, el propietario de las acciones o participaciones podrá transmitirlas libremente.

Por último, se prevé que si el socio no procediera a la transmisión de las acciones o participaciones en el plazo de dos meses, deberá iniciar de nuevo los trámites indicados anteriormente. Del examen de los plazos previstos en este artículo y de esta afirmación final, se puede deducir, fácilmente, la clara reducción de plazos que pretende la nueva regulación respecto a la normativa anterior.

En los supuestos de transmisión de acciones o participaciones que supongan un cambio de clase por razón de su propietario, los administradores sin necesidad de acuerdo de la Junta General procederán a formalizar la modificación del artículo o artículos de los estatutos a los que ello afecte, otorgando la pertinente escritura pública que se inscri- 
birá en el Registro Mercantil, una vez realizada en el Registro de Sociedades Laborales ${ }^{13}$.

Contiene la ley una nueva previsión con la finalidad de evitar el riesgo de incurrir en causa que suponga exceder los límites legales fijados a estas sociedades en el artículo 1. Así, establece que toda transmisión de acciones o participaciones, cualquiera que sea su clase y circunstancias, quedará sometida al consentimiento de la sociedad si con la misma se pueden superar los referidos límites. El consentimiento se expresará mediante acuerdo del órgano de administración en el plazo de un mes y sólo podrá denegarse si se propone, por parte de dicho órgano, la identidad de una o varias personas que adquieran las acciones o participaciones que sobrepasen los límites previstos en el artículo 1. El dictamen del CES critica el margen excesivo de facultades otorgadas al órgano de administración, al permitirle autorizar la superación de los límites del artículo 1, unido a la interpretación de cuando se pueden entender superados los mismos.

Para garantizar la seguridad jurídica precisa en la transmisión de acciones o participaciones, se prevé que si éstas no se ajustan a lo previsto en la ley, o en su caso, a lo establecido en los estatutos, no producirán efecto alguno frente a la sociedad.

Únicamente, se contempla la posibilidad de incluir cláusulas que prohíban la transmisión voluntaria de las acciones o participaciones sociales por actos «inter vivos» si los estatutos reconocen al socio el derecho a separarse de la sociedad en cualquier momento. El artículo 8 de la LSSLLyPP exige el consentimiento de todos los socios para la incorporación de estas cláusulas a los estatutos sociales.

No obstante lo indicado anteriormente, se prevé que los estatutos podrán impedir la transmisión voluntaria de las acciones o participaciones por actos «inter vivos», o el ejercicio del derecho de separación, durante un período de tiempo no superior a cinco años a contar desde la constitución de la sociedad, o para las acciones o participaciones procedentes de una ampliación de capital, desde el otorgamiento de la escritura pública de su ejecución. A este respecto, presentó una enmienda, no aceptada, el Grupo Parlamentario de UPyD para reducir ese plazo a tres años, con el argumento de que restar liquidez a las acciones de estas sociedades las perjudica y que no tiene sentido alargar tanto el plazo para liquidar una situación de este tipo, cuando se ha ampliado el fondo de reserva especial para recomprar las acciones a los trabajadores.

13 En este supuesto, en la memoria anual de las sociedades laborales se deberán recoger las variaciones de capital social que haya experimentado dicha sociedad durante el ejercicio económico de referencia. 


\subsection{Valoración de las acciones o participaciones}

Respecto a la valoración de acciones o participaciones, se mantiene como regla general que el precio de adquisición será fijado de mutuo acuerdo por las partes; y, en su defecto, por el valor razonable a la fecha de comunicación al órgano de administración del propósito de transmitir, determinado por un experto independiente. El artículo 7, realiza una aportación muy relevante, al añadir la posibilidad de que los socios de la sociedad laboral puedan acordar en los estatutos sociales los criterios y sistemas de determinación previa del valor de las acciones o participaciones para los supuestos de su transmisión o amortización, en cuyo caso prevalecerá este valor. Si se incorpora esta posibilidad una vez constituida la sociedad, no será de aplicación a los socios que no votaron a favor del acuerdo de modificación de los estatutos. Esta limitación persigue evitar posibles vulneraciones de derechos adquiridos, así como evitar el reconocimiento del derecho de separación justificada del socio disconforme con la medida adoptada.

La introducción de esta posibilidad, supone una flexibilización con el objetivo de facilitar el acceso de los trabajadores a la condición de socios, que muchas veces ven en el aspecto económico un obstáculo a tal transición. Al establecer unas condiciones de transmisión para el futuro, fijadas y conocidas desde el momento de la constitución y saber que serán aplicables, por ejemplo, las mismas condiciones económicas que se exigieron al inicio de la sociedad, puede facilitar la decisión a los trabajadores de incorporarse como socios.

\subsection{Transmisión «mortis causa»}

El artículo 10 se destina a regular estas transmisiones, estableciendo como regla general que la adquisición de acciones o participaciones sociales por sucesión hereditaria confiere al adquiriente, ya sea heredero o legatario del fallecido, la condición de socio.

Estatutariamente, se puede prever un elemento más para defender la laboralidad de la sociedad. En caso de muerte del socio trabajador, los estatutos podrán reconocer un derecho de adquisición preferente sobre las acciones o participaciones de clase laboral, por el procedimiento previsto en el artículo 6.2, y que antes hemos referido, el cual se ejercitará por el valor razonable o, en su caso, el establecido conforme a los criterios de valoración previstos estatutariamente, que tales acciones o participaciones tuvieren el día del fallecimiento del socio. Se pagará al contado, salvo que los estatutos prevean otra opción, habiendo de ejer- 
citarse este derecho de adquisición en el plazo máximo de tres meses, a contar desde la comunicación a la sociedad de la adquisición hereditaria.

No podrá ejercitarse el derecho estatutario de adquisición preferente si el heredero o legatario fuera trabajador de la sociedad con contrato de trabajo por tiempo indefinido, lo que supondría al mismo la adquisición de la condición de socio de forma automática.

Las transmisiones de acciones o participaciones, cualquiera que sea

su clase, quedarán sometidas al consentimiento de la sociedad, como ya veíamos en el caso de la transmisión voluntaria «inter vivos» si con las mismas se pudieran superar los límites previstos en el artículo 1 sobre titularidad y distribución del capital social.

\subsection{Derecho de suscripción preferente}

en toda ampliación de capital, de acuerdo con las previsiones del artículo 11, con emisión de nuevas acciones o con creación de nuevas participaciones sociales, deberá respetarse la proporción existente entre las pertenecientes a las dos clases con que puede contar la sociedad. Se establece un supuesto de excepción a esta regla de la proporcionalidad, que podrá ser incumplida cuando el aumento de capital tenga como objeto la acomodación del mismo a los límites exigidos por el artículo 1 de la ley. En estos casos, el aumento de capital podrá adoptarse por acuerdo de la junta general, siguiendo las normas de quórum y mayorías establecidas en el texto refundido de la Ley de Sociedades de Capital, aprobado por el Real Decreto Legislativo 1/2010, de 2 de julio.

Los titulares de acciones o de participaciones pertenecientes a cada una de las clases, tienen derechos de preferencia para suscribir o asumir las nuevas acciones o participaciones sociales pertenecientes a la clase respectiva.

Salvo acuerdo de la junta general que adopte el aumento del capital social, las acciones o participaciones no suscritas o asumidas por los socios de la clase respectiva se ofrecerán a los trabajadores con contrato por tiempo indefinido (esta exigencia de vinculación indefinida no se exigía en la norma anterior), en la forma prevista en el artículo $6^{14}$.

14 El artículo 11 termina con un apartado 4, que prevé que la exclusión del derecho de preferencia se regirá por la normativa vigente que resulte aplicable al tipo de sociedad, pero cuando la exclusión afecte a las acciones o participaciones de la clase laboral, la prima será fijada libremente por la junta general, siempre que la misma apruebe un plan de adquisición de acciones o participaciones por los trabajadores de la sociedad con contrato por tiempo indefinido, y que las nuevas acciones o participaciones se destinen al cumplimiento del plan e imponga la prohibición de enajenación en un plazo de cinco años. 
La regulación de un derecho de adquisición preferente es una restricción que limita la libre transmisión de acciones y participaciones, con lo cual estas pueden perder valor; pero, constituye un mecanismo más para garantizar la laboralidad de la sociedad ${ }^{15}$.

\subsection{Adquisición de la sociedad de sus propias acciones}

El artículo 12 introduce, como novedad, la regulación del régimen de autocartera, es decir, la adquisición por la sociedad laboral de sus propias acciones y participaciones sociales en los supuestos contemplados en la ley y deberá efectuarse con cargo a beneficios, a la reserva especial o a otras reservas disponibles.

Las acciones y participaciones propias adquiridas por la sociedad deberán ser enajenadas a favor de los trabajadores de la sociedad con contrato de trabajo por tiempo indefinido en el plazo máximo de tres años a contar desde la fecha de su adquisición. Si transcurrido dicho plazo, las acciones o participaciones no hubieran sido enajenadas, éstas deberán ser amortizadas mediante reducción del capital social, salvo que en su conjunto las acciones o participaciones propias no excedan del veinte por ciento del capital social.

Como mecanismo para favorecer la conversión de trabajadores en socios, se contempla expresamente que las sociedades laborales podrán anticipar fondos, conceder créditos o préstamos, prestar garantías o facilitar asistencia financiera para la adquisición de sus propias acciones o participaciones a los trabajadores de la sociedad con contrato por tiempo indefinido que no sean socios.

Las acciones y participaciones propias no computarán a los efectos de determinar si se cumple el requisito de mantener la mayoría del capital social en manos de socios trabajadores ${ }^{16}$.

En el dictamen del CES, se reconoce el papel de mecanismo regulador que puede desempeñar el instrumento de la autocartera, especialmente en relación con las necesidades de incorporación y desvinculación de los socios trabajadores; pero, considera excesivo el plazo de tres años fijado como límite para la enajenación de los títulos a los trabajadores, lo que puede contribuir a desdibujar los rasgos definitorios de las sociedades laborales.

15 FAJARDO GARCÍA, G., ALGUACIL MARÍ, P., LÓPEZ GANDÍA, J., op. cit., 2009.

16 Según el artículo 12.5, el régimen aplicable a las acciones y participaciones propias será el previsto en el artículo 148 del texto refundido de la Ley de Sociedades de Capital, aprobado por el Real Decreto Legislativo 1/2010, de 2 de julio. 


\subsection{Reserva Especial}

Además de las reservas legales o estatutarias que procedan, las sociedades laborales están obligadas a constituir una reserva especial que se dotará con el diez por ciento del beneficio líquido de cada ejercicio, hasta que alcance, al menos, una cifra superior al doble del capital social. En la legislación anterior, el fondo de reserva especial no tenía límite. Además, aunque la obligación legal era del diez por ciento, para acogerse a los beneficios tributarios se exigía a las sociedades laborales destinar al Fondo Especial de Reserva, en el ejercicio en que se produzca el hecho imponible, el 25 por 100 de los beneficios líquidos.

Una vez que la reserva no tiene el carácter de irrepartible, que recogía la ley de 1986, había que repensar su existencia y las funciones que debe garantizar ese fondo. Eran numerosas las opiniones que entendían que la reserva debe mantenerse, pero con una finalidad diferente a la que tenía originariamente, sirviendo fundamentalmente para cumplir los objetivos de garantizar el mantenimiento de la laboralidad de la sociedad, es decir, a facilitar la incorporación de trabajadores a la condición de socios. Así, Calvo Vérgez ${ }^{17}$ defendía, frente a la redacción de la ley de 1997, que el fondo debería estar previsto para que la sociedad laboral pudiera hacerse con una cartera de acciones o participaciones que permita facilitar la inclusión como socios de nuevos trabajadores.

En la actual regulación, la reserva especial sólo podrá destinarse por la sociedad laboral a la compensación de pérdidas en el caso de que no existan otras reservas disponibles suficientes para este fin, como ya se establecía en la normativa anterior, a lo que la LSSLLyPP añade la posibilidad de que se dediquen a la adquisición de sus propias acciones o participaciones sociales, que deberán ser enajenadas a favor de los trabajadores de la sociedad con contrato por tiempo indefinido, constituyendo otro mecanismo más para facilitar el acceso de los trabajadores a la condición de socio.

\subsection{Supuestos de incumplimiento de los requisitos exigidos por la normativa}

Los cambios de plazos para alcanzar otra vez los límites fijados por la LSSLLyPP para ostentar la condición de sociedad laboral son la princi-

17 CALVO VÉRGEZ, J. «Régimen fiscal de las sociedades laborales», en la obra colectiva «Fiscalidad de las entidades de economía social», director CALVO ORTEGA, R. Editorial Aranzadi, Cizur Menor 2005, p. 295. 
pal novedad, en esta materia que se regula en el artículo 1, respecto a la normativa anterior.

En los supuestos de transgresión sobrevenida de los límites establecidos respecto a la titularidad y distribución del capital social, la sociedad estará obligada a acomodar la situación de sus socios a la ley, en el plazo de dieciocho meses a contar desde el primer incumplimiento.

Si fueran superados los límites previstos de horas de trabajo por trabajadores indefinidos no socios, la sociedad deberá alcanzarlos, de nuevo, en el plazo máximo de doce meses. En este caso, el órgano del que dependa el Registro de Sociedades Laborales podrá conceder hasta dos prórrogas, por un plazo máximo de doce meses cada una de ellas, siempre que se acredite en cada solicitud de prórroga que se ha avanzado en el proceso de adaptación a los límites previstos.

Recordemos que para este caso, la normativa anterior otorgaba un plazo de treinta y seis meses para alcanzar nuevamente los límites legales, si bien exigía que se fuera reduciendo, como mínimo, cada año una tercera parte del porcentaje en el que inicialmente se exceda o supere el máximo legal.

La LSSLLyPP incluye una nueva previsión respecto a la legislación anterior, al establecer que el plazo de adaptación en los casos de subrogación legal o convencional será de treinta y seis meses, pudiendo solicitarse igualmente las prórrogas antes referidas.

\subsection{Extinción de la relación laboral del socio trabajador}

La ley dedica a este tema el artículo 9, con la finalidad de concretar el procedimiento a seguir en estos supuestos, fijando que el socio trabajador, que vea extinguida su relación laboral y en el plazo de un mes, desde la firmeza de ésta (previsión de especial importancia en los supuestos de despido), deberá ofrecer la adquisición de sus acciones o participaciones, conforme al procedimiento fijado en el artículo 6, y si nadie ejercita su derecho de adquisición, conservará la cualidad de socio, si bien las acciones o participaciones que no haya transmitido pasarán a ser de la clase general.

Se atribuye al órgano de administración la posibilidad de otorgar la venta cuando el socio, cuya relación laboral se ha extinguido, no proceda a formalizar la venta de acciones o participaciones a los interesados en su adquisición, en el plazo de un mes, desde el requerimiento notarial al efecto. Se efectuará por el valor razonable o, en su caso, el establecido conforme a los criterios de valoración previstos estatutariamente, que se consignará a disposición de aquél, bien judicialmente 
o bien en la Caja General de Depósitos o en el Banco de España. Esta transmisión forzosa no resulta habitual en la práctica de las sociedades laborales, pero la previsión puede ser válida en algún supuesto en que se origine un conflicto de esta naturaleza.

La ley prevé que los estatutos sociales podrán establecer normas especiales para diferentes supuestos que se pueden presentar en la vida de la sociedad, como los casos de jubilación e incapacidad permanente del socio trabajador, para los que accedan a la situación de excedencia, así como, y este supuesto es recogido en la ley por primera vez, para los socios trabajadores que por subrogación legal o convencional dejen de ser trabajadores de la sociedad ${ }^{18}$.

\subsection{Separación y exclusión de socios}

Se regula expresamente esta materia, a la que anteriormente le era de aplicación, exclusivamente, la legislación de las sociedades de capital. La pérdida de la calificación de la sociedad como laboral podrá ser causa legal de separación por parte del socio. Si la descalificación fuera consecuencia de un acuerdo adoptado en junta general, el derecho de separación corresponderá, únicamente, a los socios que no votaron a favor del acuerdo ${ }^{19}$.

Se contempla el supuesto de graves incumplimientos por parte del socio, que creemos que tendrá poca virtualidad en la práctica diaria de las sociedades laborales, pero que es positivo que la ley lo regule. Establece el artículo 16.3 que la sociedad laboral podrá excluir al socio que incumpla sus obligaciones en materia de transmisión de acciones y participaciones, o realice actividades perjudiciales para los intereses de la sociedad, pero exige que por éstas hubiera sido condenado por sen-

18 El artículo 9.3 fija el procedimiento en el caso de embargo de las acciones y participaciones de la sociedad o de ejecución de la prenda constituida sobre las mismas, indicando que se estará a lo previsto en el artículo 109 del texto refundido de la Ley de Sociedades de Capital, aprobado por el Real Decreto Legislativo 1/2010, de 2 de julio, con la particularidad de que las notificaciones se hagan también a los trabajadores no socios con contrato indefinido (este precepto sólo exige la notificación a los socios), y que el derecho de subrogación previsto (de la sociedad en lugar del rematante, aceptando las condiciones de la subasta y la consignación íntegra del importe del remate) se ejercite en el orden previsto en el artículo 6 la LSSLLyPP.

19 El artículo 16.2 establece que el derecho de separación en caso de falta de distribución de dividendos previsto en el artículo 348 bis del texto refundido de la Ley de Sociedades de Capital, aprobado por el Real Decreto Legislativo 1/2010, de 2 de julio, no será de aplicación a los socios trabajadores de la sociedad laboral. 
tencia firme a indemnizar a la sociedad los daños y perjuicios causados. Las acciones o participaciones de los socios separados o excluidos deberán ser ofrecidas a los trabajadores de la sociedad con contrato de trabajo por tiempo indefinido, conforme a lo previsto en el artículo 6 de la ley. Las acciones o participaciones no adquiridas deberán ser amortizadas mediante reducción del capital social.

En el plazo máximo de cuatro meses a partir de la recepción del escrito por el que el socio comunica que ejercita su derecho de separación, del acuerdo de la junta general por el que se decide la exclusión del socio, o de la notificación de la resolución judicial firme dictada al respecto, el socio separado o excluido tendrá derecho a obtener en el domicilio social el valor de sus acciones o participaciones, trasmitidas o amortizadas.

\subsection{Pérdida de la calificación}

Las causas legales de pérdida de la calificación como «sociedad laboral», de acuerdo con el artículo 15, son las siguientes:

1. ${ }^{a}$ La superación de los límites establecidos en el artículo 1 (respecto a la titularidad del capital social y su distribución y el volumen de horas de trabajo efectuadas por los trabajadores no socios con contrato indefinido), sin perjuicio de las excepciones previstas en el mismo.

2. ' La falta de dotación, la dotación insuficiente o la aplicación indebida de la reserva especial.

Verificada la existencia de una causa legal de pérdida de la calificación, cuando no se haya comunicado al correspondiente Registro de Sociedades Laborales, en el plazo de un mes desde que se produzca la causa, o en el caso de comunicación cuando hayan transcurrido los plazos de adaptación previstos en el artículo 1 (y recogidos en el apartado 2.9 anterior), el Ministerio de Empleo y Seguridad Social o el órgano competente de la comunidad autónoma correspondiente, tras la instrucción del oportuno expediente, descalificará a la sociedad como «sociedad laboral», ordenando su baja en el Registro de Sociedades Laborales. Efectuado el correspondiente asiento, se remitirá certificación de la resolución y de la baja al Registro Mercantil para la práctica de la correspondiente nota marginal en la hoja abierta a la sociedad.

El procedimiento a seguir para la descalificación deberá ser regulado en el reglamento del Registro Administrativo de Sociedades Laborales, que se apruebe próximamente. 
La Ley contempla expresamente, a diferencia de la anterior que la sociedad pueda perder la calificación de laboral por acuerdo de la Junta General, adoptado con los requisitos y las mayorías establecidas para la modificación de los estatutos, es decir, igual que la sociedad acuerda el carácter de laboral, puede acordar la pérdida de tal condición.

La descalificación como laboral conllevará la pérdida y el reintegro de los beneficios y ayudas públicas, adquiridos como consecuencia de su condición de sociedad laboral desde el momento en el que la sociedad incurra en la causa de descalificación.

La pérdida de la calificación de la sociedad como laboral no es causa automática de disolución; pero, los estatutos sociales podrán establecer ésta como causa de disolución de la sociedad.

\section{Aspectos formales y organizativos. Registro de sociedades Laborales}

\subsection{Competencia administrativa}

La competencia, según el artículo 2, para otorgar la calificación, así como para controlar el cumplimiento de los requisitos para mantener la misma y, para, en su caso, resolver sobre la descalificación corresponde al Ministerio de Empleo y Seguridad Social o, en su caso, a los órganos competentes de las comunidades autónomas que hayan recibido los correspondientes traspasos de funciones y servicios en materia de calificación y registro de sociedades laborales. Esto supone en la práctica, que, salvo para las sociedades laborales radicadas en Ceuta y Melilla, la competencia corresponda a las comunidades autónomas. En el caso de Cantabria, es la Dirección General de Trabajo, de la administración autonómica, quien asume esta competencia.

La calificación otorgada por una autoridad competente tendrá plena eficacia en todo el territorio nacional sin necesidad de que la sociedad realice ningún trámite adicional o cumpla nuevos requisitos. Esta afirmación, incluida por primera vez en la ley, confirma algo que era evidente. Una sociedad laboral calificada como tal no tiene que acreditar tal condición ante otra autoridad para realizar su actividad en el territorio de otra comunidad autónoma. Esta inclusión expresa, evita posibles conflictos al respecto.

La sociedad interesada en obtener la calificación de «laboral» presentará la correspondiente solicitud, a la que acompañará la documentación que se determine reglamentariamente. Pero, la ley exige que, en todo caso, las sociedades de nueva constitución aporten copia autori- 
zada de la escritura, en la que conste expresamente la voluntad de los otorgantes de fundar una sociedad laboral.

Si la sociedad es preexistente, deberá aportar certificación literal del Registro Mercantil sobre los asientos vigentes relativos a la misma, copia autorizada de la escritura de elevación a público de los acuerdos de la junta general favorables a la calificación de sociedad laboral y a la modificación de los artículos de sus estatutos para adaptarlos a lo previsto en la LSSLLyPP, así como del libro registro de acciones nominativas o del libro registro de socios que refleje la titularidad de las acciones o participaciones. En principio, y, a la espera de que se apruebe el reglamento del Registro, que deberá seguir esa voluntad de la ley, se opta por simplificar el procedimiento para calificar las sociedades preexistentes.

La ley prevé la modernización y agilización de los procedimientos, al establecer que los trámites necesarios para la calificación e inscripción de una sociedad como laboral podrán realizarse a través de los medios electrónicos, informáticos y telemáticos que se habiliten al efecto.

La disposición final cuarta obliga al Gobierno, para que en el plazo máximo de un año a partir de la publicación de la ley20, a propuesta de los Ministros de Justicia y de Empleo y Seguridad Social, proceda a la aprobación de un nuevo real decreto que regule el Registro Administrativo de Sociedades Laborales, con el objetivo de modernizar el funcionamiento de dicho registro, mediante la implantación de los procedimientos telemáticos, a los que se refiere el propio articulado de la ley. Dicho real decreto contemplará los correspondientes mecanismos de cooperación para hacer efectiva la integración en una base de datos común permanentemente actualizada del registro del Ministerio de Empleo y Seguridad Social de la información obrante en los registros de las comunidades autónomas que resulte necesaria para ejercer las funciones de supervisión.

Como puede apreciarse la obligación impuesta al Gobierno hace especial hincapié en los procedimientos telemáticos y el real decreto, necesariamente, deberá simplificar los procedimientos de calificación, ya que constituye uno de los objetivos de la ley, que el desarrollo reglamentario deberá respetar.

Tal vez sea conveniente, para dar cumplimiento a la última exigencia de la disposición final cuarta, la creación de una plataforma estatal, puesta en funcionamiento por el Ministerio de Empleo y Se-

20 La Ley 44/2015, de 14 de octubre, de SSLLyPP, fue publicada en el Boletín Oficial del Estado de 15 de octubre de 2015. 
guridad Social y ofrecida a las comunidades autónomas (ya que si se crean registros telemáticos independientes, se corre el riesgo de que en algunas comunidades autónomas se demore excesivamente su creación) para su utilización, dando la opción de acceder desde ella a los diferentes registros, como se hace ya con el Registro de Empresas Acreditadas para actuar como contratistas o subcontratistas en el sector de la construcción ${ }^{21}$, el Registro de Convenios Colectivos ${ }^{22}$ o el Registro de Servicios de Prevención Ajenos ${ }^{23}$. Esta fórmula permitiría, además, la creación de una base de datos nacional de sociedades laborales, que mejoraría sustancialmente la información, de la que hoy disponemos, sobre el sector.

\subsection{Registro Administrativo de Sociedades Laborales y coordinación con el Registro Mercantil}

Las sociedades laborales, como sociedades limitadas o anónimas que son, además de estar inscritas por su naturaleza laboral en el correspondiente Registro Administrativo, deben inscribirse en el Registro Mercantil. La sociedad gozará de personalidad jurídica desde su inscripción en el mismo (artículo 4.2); pero, este no practicará ninguna inscripción de modificación de estatutos de una sociedad laboral que afecte a su denominación, domicilio social, composición del capital social o régimen de transmisión de acciones y participaciones, sin que se aporte por la misma el certificado del Registro de Sociedades Laborales o la resolución favorable de que dicha modificación no afecta a la calificación de la sociedad como laboral, o bien la anotación registral del cambio de domicilio.

Los registradores mercantiles remitirán al registro administrativo correspondiente, preferentemente en formato electrónico, con lo que se mejorará la coordinación en la transmisión de información, nota simple informativa de la práctica de los asientos que afecten a la constitución y extinción de las sociedades laborales, así como a la modificación de los actos referidos en el párrafo anterior.

21 Véase el artículo 10.3 del Real Decreto 1109/2007, de 24 de agosto, por el que se desarrolla la ley 32/2006, reguladora de la subcontratación en el Sector de la Construcción.

22 Véase el artículo 5 del Real Decreto 713/2010, de 28 de mayo, sobre registro y depósito de convenios y acuerdos colectivos de trabajo.

23 Véase el artículo 28.4 del Real Decreto 39/1997, por el que se aprueba el Reglamento de los Servicios de Prevención. 
El cambio de domicilio de la sociedad laboral deberá comunicarse a la autoridad competente (de la que dependa el Registro Administrativo de Sociedades Laborales). Cuando el traslado se produzca al ámbito de actuación de otro registro administrativo, pasará a depender de éste. En cualquier caso, en el supuesto de que esté incoado un expediente de descalificación al momento del traslado, el registro de origen mantendrá la competencia hasta su resolución.

Se prevé expresamente en el artículo 4.7 que el juez que conozca de la impugnación de algún acuerdo social que afecte a la denominación, composición del capital o al cambio de domicilio, debe comunicar al registro administrativo del que dependa la sociedad la existencia de la demanda y las causas de impugnación, así como la sentencia que dicte sobre la demanda.

\subsection{Denominación social}

En la denominación de la sociedad, de acuerdo con el artículo 3, deberá figurar necesariamente la indicación «sociedad anónima laboral», "sociedad de responsabilidad limitada laboral», o "sociedad limitada laboral» o sus abreviaturas SAL, SRLL o SLL, según proceda.

Como resulta evidente, el adjetivo «laboral» no podrá ser incluido en la denominación por sociedades que no tengan otorgada tal calificación. $Y$, en sentido inverso, la denominación de «laboral» se hará constar en toda su documentación, correspondencia, notas de pedido y facturas, así como en todos los anuncios que deban publicarse por disposición legal o estatutaria.

\section{4. Órgano de administración}

Las normas generales sobre los órganos sociales serán las establecidas, con carácter general, para las sociedades de capital. La LSSLLyPP contiene algunas normas más que la ley anterior sobre el órgano de administración, afirmando, en primer lugar, en el artículo 13 que es competencia de los administradores la gestión y la representación de la sociedad. En el caso de que los administradores deleguen la dirección y gestión de la sociedad, o confieran apoderamientos con esta finalidad, deberán adoptar las medidas precisas para delimitar claramente sus competencias y evitar interferencias y disfunciones.

Si la sociedad laboral estuviera administrada por un consejo de administración, se prevé que los titulares de acciones o participacio- 
nes de la clase general pueden agrupar sus acciones o participaciones sociales para nombrar a sus miembros conforme al sistema de representación proporcional previsto en el artículo 243 del texto refundido de la Ley de Sociedades de Capital, aprobado por el Real Decreto Legislativo 1/2010, de 2 de julio. Esta nueva redacción consagra la voluntariedad de este sistema proporcional, frente a la obligatoriedad que establecía la regulación anterior.

Se establecen unos criterios específicos que deben regir la actuación de los administradores, en las que se resalta el carácter de entidades de economía social de las sociedades laborales. Establece que la administración debe ser diligente, leal, responsable, transparente y adecuada a las peculiaridades de la sociedad laboral como modelo de sociedad específico. Deberán favorecer la generación de empleo estable y de calidad, la integración como socios de los trabajadores, la igualdad de oportunidades entre hombres y mujeres, y la conciliación de la vida personal, familiar y laboral. Asimismo, adoptarán políticas o estrategias de responsabilidad social, fomentando las prácticas de buen gobierno, el comportamiento ético y la transparencia.

Este catálogo puede considerarse parte del ideario de la función social que deben desempeñar estas empresas, en cuanto integrantes del sector de la economía social, incidiendo en las peculiaridades básicas de este modelo empresarial que persigue la máxima integración de trabajadores como socios. Son válidas como pautas que deben guiar las actuaciones de estas sociedades y de sus responsables, pero su virtualidad jurídica, hay que reconocerlo, es mínima.

\subsection{Adaptación de estatutos}

Las sociedades laborales preexistentes deberán adaptar sus estatutos a las previsiones de la LSSLLyPP, según su disposición transitoria segunda, en el plazo máximo de dos años desde su entrada en vigor. Transcurrido ese plazo, no se inscribirá en el Registro Mercantil documento alguno de la sociedad laboral hasta que no se haya inscrito la adaptación de los estatutos sociales. Se exceptúan de esta prohibición de inscripción el acuerdo de adaptación a la propia ley, los títulos relativos al cese o dimisión de administradores, gerentes, directores generales y liquidadores, y la revocación o renuncia de poderes, así como a la transformación de la sociedad o su disolución, nombramiento de liquidadores, liquidación y extinción de la sociedad y los asientos ordenados por la autoridad judicial o administrativa. 
El contenido de la escritura pública y estatutos de las sociedades laborales calificadas e inscritas al amparo de la normativa anterior que es derogada por la LSSLLyPP no podrá ser aplicado en oposición a lo dispuesto en ésta.

\section{Régimen de Seguridad Social de los socios trabajadores}

La condición de accionista o partícipe del trabajador en la sociedad genera una problemática específica en materia de encuadramiento de los socios en el sistema de Seguridad Social.

Nos encontramos, como explica López i Mora, ${ }^{24}$ ante un supuesto de dualidad contractual. El nexo entre los socios trabajadores y la empresa tiene verdadera naturaleza laboral; pero, a la vez, estas organizaciones responden al patrón de las sociedades de capitales, donde no es posible contribuir al fondo común de la sociedad con la aportación del trabajo personal como ocurre en las sociedades personalistas. Por lo que estamos en la confluencia de dos contratos, el de trabajo y el de sociedad.

No obstante, puede haber supuestos en los que los socios trabajadores estén vinculados a la sociedad por una relación en la que falte alguno de los elementos esenciales del contrato de trabajo. Para ello, debemos atender a dos supuestos fundamentales:

Nivel de aportación económica del socio trabajador al capital social de la sociedad, lo que nos va a permitir comprobar si se desvirtúa o no la nota de la ajenidad, propia de todo contrato de trabajo.

Atribuciones otorgadas al socio respecto a la gestión y administración de la sociedad, lo que nos determinará el nivel de subordinación a la estructura organizativa y directiva. La falta de subordinación al poder de dirección del empresario en la vertiente organizativa, directiva o disciplinaria, también, determinará la falta de laboralidad.

La ley establece, con carácter general, en un tercio, el máximo porcentaje de capital social en manos de un socio trabajador, entendiendo que manteniéndose en esos límites, permanece la nota de ajenidad; y, por tanto, la laboralidad de la relación.

Por otro lado, entiende que si tiene gran capacidad para intervenir en el gobierno de la sociedad puede cuestionar la existencia de relación laboral, al fallar la nota de subordinación al poder empresarial.

24 LÓPEZ i MORA, F. «Problemática laboral de los socios trabajadores de las empresas de Economía Social: ¿socios o trabajadores? CIRIEC-España, Revista de Economía Pública, Social y Cooperativa, n. ${ }^{\circ}$ 31, junio 1999, pp. 9-46. 
Se puede presentar una tercera opción, es el caso de las sociedades laborales controladas efectivamente por un grupo familiar, en cuyo caso no cabe hablar de relación laboral de los socios integrados en ese grupo que dispone de la mayoría del capital social.

La disposición final primera de la Ley 44/2015, de 14 de octubre ${ }^{25}$, se dedica a la regulación de este aspecto, modificando el texto refundido de la Ley General de la Seguridad Social, aprobado por Real Decreto Legislativo 1/1994, de 20 de junio. Con posterioridad a la aprobación de la LSSLLyPP, se publica el Real Decreto Legislativo 8/2015, de 30 de octubre, por el que se aprueba el texto refundido de la Ley General de Seguridad Social26. Se contemplan tres supuestos diferentes, en función de las circunstancias que hemos expuesto anteriormente:

1. Regla general. En la mayoría de los supuestos procederá la inclusión en el Régimen General. De acuerdo con el artículo 136.2 d) del nuevo texto refundido de la Ley General de Seguridad Social están expresamente incluidos en el Régimen General los socios trabajadores de las sociedades laborales, cuya participación en el capital social se ajuste a lo establecido en la LSSLLyPP y aun cuando sean miembros de su órgano de administración, si el desempeño de este cargo no conlleva la realización de las funciones de dirección y gerencia de la sociedad y no posean el control de la sociedad.

2. Asimilación a trabajadores por cuenta ajena. Los socios trabajadores se integrarán como asimilados a trabajadores por cuenta ajena, con exclusión de la protección por desempleo y del Fondo de Garantía Salarial, salvo que el número de socios de la sociedad laboral no supere los 25 , cuando por su condición de administradores sociales realicen funciones de dirección y gerencia de la sociedad, siendo retribuidos por ello o por su vinculación simultánea a la sociedad laboral mediante una relación laboral de carácter especial de alta dirección. Esta excepción para las empresas de menos de 25 socios no operaba en la normativa anterior.

Esta medida puede producir un efecto negativo para estas sociedades, al desincentivar a los socios para asumir funciones directivas y gerenciales, ya que por aceptar las mismas, pueden

25 Opta por incluir modificaciones en la legislación específica de Seguridad Social, en lugar de integrar las normas en esta materia en el texto de la ley, como ocurría en la Ley 24/1997.

26 Esta norma está vigente desde 2 de enero de 2016. 
ser objeto de minoración en la cobertura de la acción protectora de la Seguridad Social.

Como observación, se debe aclarar que en los dos casos anteriores, la inclusión no se producirá en el Régimen General cuando por razón de su actividad, los socios trabajadores de las sociedades laborales deban quedar comprendidos como trabajadores por cuenta ajena o como asimilados a ellos en algún régimen especial de la Seguridad Social.

3. Asimilación a trabajadores por cuenta propia. Esta ley añade la disposición adicional vigésima séptima bis a la Ley General de Seguridad Social de 1994, que en el nuevo texto refundido se incluye en el artículo 305. 2 d) y regula el supuesto de inclusión de los socios trabajadores de sociedades laborales en la Seguridad Social como trabajadores por cuenta propia, cuando su participación en el capital social junto con la de su cónyuge y parientes por consanguinidad, afinidad o adopción hasta el segundo grado con los que convivan alcance, al menos, el cincuenta por ciento, salvo que acredite que el ejercicio del control efectivo de la sociedad requiere el concurso de personas ajenas a las relaciones familiares. En este caso, quedarían encuadrados en el Régimen Especial de la Seguridad Social para los Trabajadores Autónomos.

En este supuesto, merece especial atención la sociedad compuesta únicamente por dos socios trabajadores que la ley contempla como posibilidad transitoria al inicio de la vida de la misma. Por imperativo legal, los dos socios deberán distribuirse el capital social al cincuenta por ciento. En este caso, ambos socios, quedarán integrados necesariamente en el Régimen Especial de la Seguridad Social para los Trabajadores Autónomos, al alcanzar su participación el porcentaje antes referido.

\section{Régimen fiscal de las sociedades laborales}

Los beneficios fiscales a este tipo de entidades encuentran fácil justificación en el mandato constitucional que obliga a los poderes públicos a promover la participación de los trabajadores mediante el acceso a la titularidad de los medios de producción.

Pese a ello, en la LSSLLyPP se hace una sola referencia al tratamiento fiscal, al afirmar en el artículo 17 que las sociedades que sean calificadas como laborales gozarán, en el Impuesto sobre Transmisiones 
Patrimoniales y Actos Jurídicos Documentados, de una bonificación del 99 por 100 de las cuotas que se devenguen por modalidad de transmisiones patrimoniales onerosas, de bienes y derechos provenientes de la empresa de la que proceda la mayoría de los socios trabajadores de la sociedad laboral.

Como puede apreciarse, el único requisito impuesto para poder acogerse a estos beneficios es la calificación como laboral, suprimiéndose el requisito previsto en el artículo 20 de la Ley 4/1997 de destinar al Fondo Especial de Reserva, en el ejercicio en que se produzca el hecho imponible, el 25 por 100 de los beneficios líquidos. Si la sociedad no tiene la calificación de laboral, aunque reúna los requisitos para serlo no podrá acogerse a estos beneficios.

Ante esto, no cabe hablar de que se regule un régimen fiscal de las sociedades laborales ${ }^{27}$, ya que en el marco de la LSSLLyPP se limita a contemplar los beneficios del ITPyAJD. No recoge un tratamiento fiscal integral de la sociedad laboral.

La medida fiscal más importante a la que pueden acogerse las sociedades laborales es la libertad de amortización de los elementos del inmovilizado material, intangible e inversiones inmobiliarias, adquiridos durante los primeros cinco años desde la calificación como tal, que se regula en la Ley del Impuesto de Sociedades; pero, esta medida ha perdido su carácter de promoción al extenderse, con matizaciones, a las empresas de pequeña dimensión en general.

La normativa fiscal debería contemplar y favorecer los supuestos de existencia de planes de adquisición de acciones y participaciones por parte de los trabajadores, que la empresa financie la adquisición o suscripción de éstas e incentivar las inversiones realizadas por los trabajadores para acceder o mantener la condición de socio, lo que exigiría establecer normas específicas en el Impuesto sobre la Renta de las Personas Físicas de los socios trabajadores y en el Impuesto de Sociedades respecto a estas entidades.

Con lo cual, podemos concluir que las ventajas fiscales otorgadas a las sociedades laborales son escasas. No afectan a los tributos que vertebran nuestro sistema fiscal, por lo que no creemos que el mandato constitucional de fomento de participación de los trabajadores en la empresa, se encuentre cumplido en esta materia.

Esta insuficiencia quedó patente en el debate parlamentario de aprobación de la LSSLLyPP, donde señaló, expresamente, el portavoz de Convergencia i Unió en el Congreso de los Diputados, que la re-

27 SUBERBIOLA GARBIZU, I., op. cit., p.23. 
gulación de los incentivos fiscales se queda corta y manifestó que ésta será una cuestión pendiente para la próxima legislatura, que, como sabemos, por su brevedad no ha afrontado esta tarea.

\section{Medidas de fomento}

La disposición adicional cuarta se dedica a las medidas de fomento para la constitución de sociedades laborales y la creación de empleo, estableciendo que serán de aplicación a los socios trabajadores de las sociedades laborales todos los beneficios que, en el ámbito de empleo y de la seguridad social, y en desarrollo de la Ley 5/2011, de 29 de marzo, de Economía Social, tengan por objeto impulsar la realización de actuaciones de promoción, difusión y formación de la economía social.

Como hemos repetido con insistencia, el artículo 129.2 de la CE exige la regulación de mecanismos que faciliten el acceso de los trabajadores a los medios de producción, en el marco más amplio de un régimen de participación de los mismos en la empresa.

No podemos ocultar que existen voces discrepantes con la existencia de medidas específicas favorecedoras de las empresas de economía social, especialmente en el caso de las cooperativas, por ser éstas las que tienen un régimen fiscal propio; pero, los motivos para que estas medidas existan son claros. Estas sociedades gozan de principios y valores (gestión democrática, prioridad de la persona sobre el capital,...), así como de ventajas y potencialidades (creación de empleo estable y de calidad, fijación de población al territorio, generación de cohesión social, contribución al desarrollo local,...) que las hacen merecedoras de un tratamiento específico. Así, lo reconoce el preámbulo de la Ley $31 / 2015$, de 9 de septiembre, por la que se modifica y actualiza la normativa en materia de autoempleo y se adoptan medidas de fomento y promoción del trabajo autónomo y de la economía social28, al reconocer que ésta es fuente de creación de empleo estable, de calidad y no deslocalizable y es una importante plataforma de acceso al empleo para aquellos que, por sus especiales circunstancias, encuentran mayores dificultades de inserción laboral y/o que se encuentran en riesgo de exclusión social. Constituyen, añade, un elemento clave de cohesión social muy necesario tras la larga crisis que ha atravesado nuestro país.

28 Esta ley modifica el artículo 9 de la Ley 5/2011, de 29 de marzo, de Economía Social, estableciendo incentivos a la incorporación de trabajadores a entidades de economía social. 
Para confirmar que estas empresas pueden tener un régimen fiscal favorable sin que sean consideradas ayudas de estado (prohibidas por la normativa comunitaria), Calvo Ortega ${ }^{29}$ explica que estas prácticas no son ilegales cuando no se favorece a empresas o producciones para falsear la competencia y se trata de una fiscalidad horizontal para un grupo genérico de empresas no vinculados a un territorio ni a una producción concreta.

La Administración General del Estado, así como las Administraciones de las Comunidades Autónomas con competencias en materia de economía social deben elaborar programas estructurados de fomento de la economía social, no adoptar medidas dispersas, inconexas y reiterativas, como ocurre habitualmente, aunque no hayan demostrado su utilidad. Se debe partir del análisis de los verdaderos resultados de las medidas implementadas con anterioridad y de la fijación de los objetivos que se pretenden conseguir para determinar las medidas que se deben ejecutar en el futuro.

Estas medidas, una vez constatada su eficacia, tienen que ser estables en el tiempo y no estar sujetas a eventualidades económicas o cambios políticos, para ofrecer seguridad a los eventuales promotores de este tipo de empresas de cuál va a ser la actitud de las entidades públicas respecto a sus proyectos empresariales.

Para conseguir que la figura de la sociedad laboral cale en el mundo del emprendimiento hay que conseguir que ésta sea más conocida de lo que realmente lo es en la actualidad, tanto por parte de los trabajadores y sus representantes, como por los potenciales emprendedores futuros, es decir, los estudiantes universitarios y de enseñanzas medias. Es necesario dar a conocer las figuras empresariales de economía social a los profesionales que asesoran a los potenciales emprendedores, ya que los prescriptores de formas jurídicas empresariales no ofrecen estas fórmulas, habitualmente, a las personas que se acercan a ellos con un proyecto empresarial.

También, sería necesaria la formación específica de los socios trabajadores, ya que ellos son los responsables de fijar los criterios de gestión y los objetivos de la misma, además de conocer en profundidad el modelo empresarial por el que han optado.

En los programas de formación y difusión vemos constantemente la celebración de congresos, seminarios, encuentros, cursos, ... en los que los participantes son de forma reiterada los estudiosos del tema, los dirigentes del movimiento asociativo o de las empresas de econo-

29 CALVO ORTEGA, R., op. cit. 2013, pp. 69-78. 
mía social más importantes, los responsables de la materia en las administraciones públicas; pero, no acceden a ellos los promotores de empresas asociativas, los que antes denominábamos prescriptores de formas jurídicas empresariales (asesores, agentes de desarrollo local, orientadores de empleo, personal de las Cámaras de Comercio,...) que son los que tienen la llave para la creación efectiva de sociedades laborales.

Tanto la LES como las leyes de cooperativas reclaman la enseñanza del cooperativismo y la economía social en los diferentes niveles educativos. Esto es algo que está pendiente y parece que aún muy lejana su consecución. Se llega a un puñado de centros de enseñanza secundaria a los que se acercan las entidades asociativas del sector a presentar estos modelos empresariales y a un reducido número de centros universitarios que realizan acciones de difusión, normalmente financiadas con cargo a programas públicos de fomento; pero, no se introduce el estudio de las fórmulas empresariales de economía social, salvo muy loables excepciones, en los programas educativos.

Por otro lado, tenemos que valorar que las medidas que existen actualmente, han visto claramente reducidas las posibles ventajas competitivas para las sociedades laborales. Así, la capitalización de la prestación por desempleo prevista en el Real Decreto 1044/1985, de 19 de junio, por el que se regula el abono de la prestación por desempleo en su modalidad de pago único por el valor actual de su importe, como medida de fomento de empleo, se ha generalizado para el inicio de la actividad profesional por parte de los trabajadores autónomos. Lo mismo podemos decir de la libertad de amortización de los elementos del inmovilizado material, que se ha generalizado a las empresas de pequeña dimensión, a la que nos referimos en el apartado de medidas fiscales.

Con estos datos, podemos concluir que se ha producido una pérdida de las ventajas competitivas que podían tener en otra época las empresas de economía social y que aconsejan una revisión de las políticas de fomento de éstas; pero, insistimos, que se deben adoptar medidas que resulten realmente eficaces para alcanzar el objetivo de conseguir ofrecer una imagen atractiva de las sociedades laborales a los emprendedores.

\section{Asociacionismo}

La disposición adicional segunda de la LSSLLyPP reconoce el derecho de las sociedades laborales a organizarse en asociaciones o agru- 
paciones específicas, de conformidad con la Ley 19/1977, de 1 de abril, reguladora del derecho de asociación sindical.

Las funciones que deben desempeñar éstas son de representación de las sociedades laborales ante las administraciones públicas y en defensa de sus intereses, así como para organizar servicios de asesoramiento, formación, asistencia jurídica o técnica en beneficio de sus asociados.

Se otorgan, habitualmente, ayudas públicas para el mantenimiento de las estructuras de las organizaciones representativas del sector, financiando sus gastos ordinarios sin exigir ninguna contrapartida. Debe de financiarse a estas entidades, pero como compensación por su labor en la creación de empresas de economía social, de puestos de trabajo, de servicios efectivos prestados a sus asociados, de actividades de divulgación... De esta manera, se conseguiría una mayor efectividad de los recursos públicos y una vinculación directa a la actividad que realizan las organizaciones en favor de la creación y consolidación de empresas.

Las sociedades laborales tienen que vencer la sensación de aislamiento dentro de un mundo empresarial tan dimensionado, para eso hay que reforzar las estructuras asociativas de estas empresas, logrando que estas entidades sean interlocutores realmente tenidos en cuenta por las diferentes administraciones públicas en la fijación de las políticas públicas de fomento de la economía social.

\section{La regulación de las sociedades participadas en la Ley de Sociedades Laborales y Participadas}

Como decíamos anteriormente, se dedica el Capítulo III de la ley a la regulación de las sociedades participadas por los trabajadores. Este capítulo es el que ha resultado más polémico en el procedimiento de elaboración y aprobación de la LSSLLyPP.

La participación de los trabajadores en la empresa puede presentar diversas modalidades, ya que ésta puede ser en la gestión, en los beneficios o en la propiedad. Pero, en cualquier caso, la participación puede ser un elemento clave para la pervivencia, modernización y desarrollo de las empresas. No obstante, nos encontramos con aspectos muy importantes que dificultan el incremento de las sociedades participadas y son básicamente la concepción de las relaciones laborales como conflicto entre las partes y la dualidad extrema entre la cultura de propiedad y la cultura de dependencia. A lo que hay que añadir que los momentos de crisis económica no resultan los más atractivos para incentivar esa participación por parte de los trabajadores. 
El mandato constitucional para facilitar el acceso de los trabajadores a los medios de producción, entiende Alguacil Mari 30 , no tiene que concretarse necesariamente a través de un tipo social específico, ni siquiera a través de entidades encuadradas en la economía social. No obstante, en España, la sociedad laboral es la referencia de las sociedades participadas, constituyendo un modelo idóneo para la consecución de los objetivos propuestos por el artículo 129.2 de la C.E.; pero la ley ha querido ampliar el concepto de este tipo de sociedades y dar los primeros pasos para contribuir a la visibilidad de éstas, que actualmente es muy escasa.

\subsection{Fundamento y principios}

En primer lugar, se impone a los poderes públicos, en el artículo 18, la obligación de promover la constitución y desarrollo de las sociedades participadas por los trabajadores, porque se considera que la participación de éstos en los resultados y en la toma de decisiones de las sociedades contribuye al aumento de la autonomía del trabajador en su lugar de trabajo, y fomenta la colaboración en la estrategia futura de la empresa.

Se establecen, en el artículo 18.3, los principios a los que se someten las sociedades participadas por los trabajadores, que son:

a) Promoción del acceso de los trabajadores al capital social y/o a los resultados de la empresa.

b) Fomento de la participación de los trabajadores en la toma de decisiones de la sociedad.

c) Promoción de la solidaridad interna y con la sociedad que favorezca el compromiso con el desarrollo local, la igualdad de oportunidades entre hombres y mujeres, la cohesión social, la inserción de personas en riesgo de exclusión social, la generación de empleo estable y de calidad, la conciliación de la vida personal, familiar y laboral y la sostenibilidad.

\subsection{Concepto de sociedad participada por los trabajadores}

El artículo 19 define el concepto de Sociedad Participada por los Trabajadores, estableciendo que tendrán tal consideración aquellas so-

30 ALGUACIL MARÍ, M.P., "La tributación de las Sociedades Laborales. Thomson Aranzadi, Cizur Menor, 2007. 
ciedades anónimas o de responsabilidad limitada que no alcancen los requisitos establecidos para obtener la calificación como sociedad laboral, pero promuevan el acceso a la condición de socios de los trabajadores, así como las distintas formas de participación de los mismos, en particular a través de la representación legal de los trabajadores. Deben, además, de cumplir alguno de los siguientes requisitos:

a) Que cuenten con trabajadores que posean participación en el capital y/o en los resultados de la sociedad.

b) Que cuenten con trabajadores que posean participación en los derechos de voto y/o en la toma de decisiones de la sociedad.

c) Que adopten una estrategia que fomente la incorporación de trabajadores a la condición de socios.

d) Que promuevan los principios recogidos en el artículo 18, antes referidos.

Se establecen unos principios que tienen que inspirar la actuación de estas empresas que deberá ser diligente, leal, responsable y transparente, y deberán favorecer la generación de empleo estable y de calidad, la integración como socios de los trabajadores, la igualdad de oportunidades entre hombres y mujeres, y la conciliación de la vida personal, familiar y laboral.

Asimismo, adoptarán políticas o estrategias de responsabilidad social, fomentando las prácticas de buen gobierno, el comportamiento ético y la transparencia.

\subsection{Reconocimiento}

El artículo 20, establece que podrán ser reconocidas como sociedades participadas por los trabajadores, aquellas que cumplan con las exigencias de la ley. Remite expresamente a desarrollo reglamentario, por parte del Ministerio de Empleo y Seguridad Social, la regulación del procedimiento para otorgar este reconocimiento; pero, no aclara nada la ley sobre la naturaleza del mismo y los posibles efectos que pueda suponer tal reconocimiento para la empresa.

Por último, prevé que las administraciones públicas podrán adoptar, en el ámbito de sus competencias, medidas que, de forma armonizada y coordinada, promuevan e impulsen la participación de los trabajadores en las empresas, lo que supone otra declaración necesitada de desarrollo.

La disposición final quinta, que habilita al Gobierno para dictar las disposiciones necesarias para el desarrollo reglamentario de la ley, se 
refiere, en concreto, a la necesaria regulación de lo referente al régimen aplicable a las sociedades participadas por los trabajadores.

\subsection{Críticas a esta regulación}

En el dictamen del CES al anteproyecto de LSSLLyPP, partiendo de la consideración como necesaria de la regulación de las sociedades participadas, defiende que ésta debe ser mucho más completa y precisa de la que contiene el texto dictaminado. Entiende, asimismo, que su regulación debe ser fruto de un proceso de diálogo y consenso con los interlocutores sociales. Señala que la regulación del capítulo III resulta parca e insuficiente, a la vez que se habilita al Gobierno para desarrollar dicho régimen, lo que no parece adecuado desde una óptica de correcta política legislativa. Considera el CES que no establece la ley unas líneas claras y suficientes para el ulterior desarrollo reglamentario.

EI CES considera conveniente que la regulación de estas sociedades contenga una aproximación integral de la participación de los trabajadores en las empresas, recogiendo expresamente los aspectos de participación de los representantes de los trabajadores. A la vez, entiende que las políticas de impulso y promoción de sociedades participadas deben ser concretadas en mayor medida en la ley.

Esta falta de diálogo y consenso con los interlocutores sociales y la parquedad de la regulación propuesta son los motivos esgrimidos en las enmiendas al respecto presentadas en la fase de debate y aprobación en las Cortes Generales de la ley por diferentes grupos parlamentarios, que pretendían la supresión del capítulo III en su integridad y de la habilitación específica al Gobierno para el desarrollo reglamentario de esta materia, que como se señalaba anteriormente, se ha convertido en la más polémica de la ley.

\section{Conclusiones}

La primera cuestión a plantearnos es si resultaba necesaria una nueva ley o era suficiente con modificar la Ley 4/1997, dados los pocos cambios operados en el régimen de sociedades laborales. La justificación a la aprobación de una nueva ley se puede encontrar en la inclusión de la regulación que se hace de las sociedades participadas, que se presenta como la gran novedad de esta ley. Pero la misma es escueta y no se profundiza nada en su régimen y se abre un am- 
plio proceso de desarrollo reglamentario, muy criticado, como hemos visto. Por tanto, tal vez habría sido conveniente una nueva ley que reformase el anterior régimen de las sociedades laborales, pero que incluyese una amplia, clara y consensuada regulación de las sociedades participadas por los trabajadores. Al no hacer esto, podría haberse optado únicamente por la modificación, en la ley 4/1997, del régimen de las sociedades laborales.

Es evidente la parquedad de la regulación de las sociedades participadas y la amplitud otorgada al Gobierno para un futuro desarrollo reglamentario. La norma es muy escueta y, a la vez, muy abierta en la formulación de la idea misma de estas sociedades.

Para facilitar la conservación del rasgo de laboralidad, la nueva ley pone a disposición de las sociedades laborales una serie de mecanismos jurídicos, como son, el derecho de adquisición preferente, el régimen preferente en la ampliación de capital, las reservas que faciliten la entrada de socios, límites al volumen de trabajado de trabajadores indefinidos no socios, a la participación en el capital de los no trabajadores y de los socios individualmente considerados Algunas de las medidas reguladas dotan de mayor flexibilidad a estas sociedades para poder obtener y mantener la calificación como laboral. El exceso de flexibilidad se aprecia, como hemos visto de forma especial, en el fuerte incremento del número de horas-año de trabajo que pueden ser realizadas por trabajadores indefinidos no socios.

Se proponen medidas para facilitar el acceso de los trabajadores a la condición de socios. Este es uno de los objetivos básicos que deben perseguir las sociedades laborales, dada su naturaleza de empresas de economía social, cual es que la inmensa mayoría de trabajadores de la misma tengan, también, un vínculo societario.

Por último, queremos resaltar que a la ley le ha faltado valentía para tratar a fondo los temas de fomento de las sociedades laborales y su régimen fiscal. No hay que olvidar que los trabajadores comprometen su patrimonio en estos proyectos; $y$, normalmente, carecen de conocimientos de gestión financiera y se encuentran con las reticencias de las entidades para facilitar financiación a estas empresas. La concesión de subvenciones y otras fórmulas de apoyo económico a estas empresas, como hemos dicho, tienen justificación política y constitucional.

\section{Bibliografía}

Alguacil Marí, M.P. «La tributación de las Sociedades Laborales». Thomson Aranzadi, Cizur Menor, 2007. 
Calvo Ortega, R. "Las figuras de la Economía Social en la Constitución Española de 1978». CIRIEC-España, n. ${ }^{\circ}$ 47, 2003, pp. 159-174.

Calvo Ortega, R. «Entidades de Economía Social: Razones de una fiscalidad específica», en «Fiscalidad de las entidades de Economía Social», ThomsonCivitas, Cizur Menor, 2005, pp. 33-63.

Cavo Ortega, R. «Sociedades Laborales». Cuadernos Civitas. Editorial Aranzadi. Cizur Menor 2013.

CALVo VéRGEZ, J. «Régimen fiscal de las sociedades laborales», en la obra colectiva «Fiscalidad de las entidades de economía social», Editorial Aranzadi, Cizur Menor 2005.

Consejo Económico y Social. «Dictamen 6/2015». Disponible en www.ces.es

Fajardo García, G., Alguacil Marí, P., López Gandía, J. «Propuesta de reforma de la Ley de Sociedades Laborales 4/1997», en "Análisis sobre los cambios normativos necesarios para cooperativas y sociedades laborales para su adaptación al nuevo escenario económico». Ministerio de Trabajo e Inmigración, 2009.

LÓPEZ I MORA, F. «Problemática laboral de los socios trabajadores de las empresas de Economía Social: ¿socios o trabajadores?» CIRIEC-España, Revista de Economía Pública, Social y Cooperativa, n. ${ }^{\circ} 31$, junio 1999, pp. 9-46.

Montesinos Oltra, S. "La Ley de Economía Social, interés general y regímenes tributarios especiales». CIRIEC-España, Revista Jurídica n. ${ }^{\circ}$ 23/2012, pp. 1-27.

Rodrigo Ruiz, M.A. "Mandato constitucional de fomento y fiscalidad de las cooperativas». CIRIEC-España, n. ${ }^{\circ} 47,2003$, pp. 199-219.

Suberbiola Garbizu, I. "Régimen tributario de las sociedades. Propuesta de reforma». CIRIEC n. ${ }^{\circ} 10,2013$, pp. 7-52. 